\title{
Preliminary Reliability and Availability Analysis of the Heber Geothermal Binary Demonstration Plant
}

\author{
AP-2085 \\ Research Project 1900-2 \\ Final Report, October 1981
}

Prepared by

ARINC RESEARCH CORPORATION

a Subsidiary of Aeronautical Radio, Inc.

2551 Riva Road

Annapolis, Maryland 21401

Principal Investigators

H. Himpler

J. White

J. Witt

Prepared for

Electric Power Research Institute

3412 Hillview Avenue

Palo Alto, California 94304

DISTRIBUTION OF THLS DOCUMEET IS UHLHATED

EPRI Project Manager

J. Weiss

Geothermal Power Systems Program

Advanced Power Systems Division 


\section{DISCLAIMER}

This report was prepared as an account of work sponsored by an agency of the United States Government. Neither the United States Government nor any agency Thereof, nor any of their employees, makes any warranty, express or implied, or assumes any legal liability or responsibility for the accuracy, completeness, or usefulness of any information, apparatus, product, or process disclosed, or represents that its use would not infringe privately owned rights. Reference herein to any specific commercial product, process, or service by trade name, trademark, manufacturer, or otherwise does not necessarily constitute or imply its endorsement, recommendation, or favoring by the United States Government or any agency thereof. The views and opinions of authors expressed herein do not necessarily state or reflect those of the United States Government or any agency thereof. 


\section{DISCLAIMER}

Portions of this document may be illegible in electronic image products. Images are produced from the best available original document. 


\section{ORDERING INFORMATION}

Requests for copies of this report should be directed to Research Reports Center (RRC), Box 50490, Palo Alto, CA 94303, (415) 965-4081. There is no charge for reports requested by EPRI member utilities and affiliates, contributing nonmembers, U.S. utility associations, U.S. government agencies (federal, state, and local), media, and foreign organizations with which EPRI has an information exchange agreement. On request, RRC will send a catalog of EPRI reports.

EPRI authorizes the reproduction and distribution of all or any portion of this report and the preparation of any derivative work based on this report, in each case on the condition that any such reproduction, distribution, and preparation shall acknowledge this report and EPRI as the source.

\section{NOTICE}

This report was prepared by the organization(s) named below as an account of work sponsored by the Electric Power Research Institute, Inc. (EPRI). Neither EPRI, members of EPRI, the organization(s) named below, nor any person acting on behalf of any of them: (a) makes any warranty, express or implied, with respect to the use of any information, apparatus, method, or process disclosed in this report or that such use may not infringe private ly owned rights; or (b) assumes any liabilities with respect to the use of, or for damages resulting from the use of, any information, apparatus, method, or process disclosed in this report.

Prepared by

ARINC Research Corporation

Annapolis, Maryland 
ABSTRACT

This report presents an assessment of the reliability and availability of the Heber Geothermal Binary Demonstration Plant on the basis of preliminary design information. It also identifies and ranks components of the plant in order of their criticality to system operation and their contribution to system unavailability. The sensitivity of the various components to uncertainties of data and the potential for reliability growth are also examined. The assessment results were obtained through the adaptation and application of an existing reliability and availability methodology to the Heber plant design. These preliminary assessments were made to assist (1) in evaluating design alternatives for the plant and (2) in demonstrating that the closed1oop, multiple-fluid, binary cycle geothermal concept is competitive with the more conventional flashed steam cycle technology.

The Heber Geothermal Binary Demonstration Plant Project is a cooperative effort of the Department of Energy, the Electric Power Research Institute, the San Diego Gas and Electric Company, and other organizations directed toward accelerating geothermal development for power generation and establishing the binary cycle technology as a proven alternative to the flashed steam cycle for moderate temperature hydrothermal resources. The binary power plant would have a capacity of $45 \mathrm{MW}$ net and would derive its energy from the low salinity $(14,000 \mathrm{ppm})$, moderate temperature $\left(360^{\circ} \mathrm{F}\right.$, $182^{\circ} \mathrm{C}$ ) fluid from the Heber reservoir in southern California. 


\section{EPRI PERSPECTIVE}

\section{PROJECT DESCRIPTION}

This final report on RP1900-2, entitled Preliminary Reliability and Availability Analysis of the Heber Geothermal Binary Demonstration Plant, is a joint effort of the Geothermal Power systems Program and the Reliability Subprogram of the Advanced Power Systems Division.

This project was an application of reliability and availability models that were developed and maintained by the Advanced Power Systems Division to help assure that all systems are evaluated on a consistent basis and to enhance the success of individual projects within the division. The analysis was based on preliminary design information. The reliability-availability model was adapted for use in this project from a model originally developed by the ARINC Research Corporation, and failure rate data were derived from a variety of sources including two electric power utilities, the North American Electric Reliability Council, manufacturers, users, and others. Availability sensitivity to component failure rate was analyzed, and an estimate of reliability growth potential was developed.

\section{PROJECT OBJECTIVES}

The project was undertaken to assess the probable reliability and availability of a binary-cycle geothermal power plant of advanced design. The purpose of the assessment was to help develop a philosophy for an availability enhancement program. In the demonstration plant, heat is exchanged between the geothermal fluid, a hot brine, and a secondary working fluid, a hydrocarbon, which drives the turbine.

\section{PROJECT RESULTS}

This binary plant appears to be capable of higher reliability and availability than otberwise comparable single-fluid geothermal units. The long-term effectiveness is estimated at 80.58 (a measure equivalent to availability but not including scheduled maintenance). It is expected that this can grow to $89.7 \%$ within 10 years by making certain modifications and additions. 
These results are based on a limited quantity of data gathered during this study. However, sensitivity analyses have shown how results vary if the data used are significantly different. For example, the data used for the brine-hydrocarbon heat exchangers are a mean time between failures (MTBF) of 1980 hours and a mean time to restore (MTTR) of 168 hours. If either the MTBF or the MTTR are improved by a factor of 4, the system effectiveness increases by 4.48. The long-term effectiveness value of 80.58 would go to 84.98 if the exchangers are 4008 better, i.e., a MTBF of 7920 hours, or to 67.18 if they are 758 worse, i.e., a MTBF of 495 hours. Although the heat exchangers are the most sensitive subsystem, other subsystems are fairly sensitive as well. As a consequence, it is important to improve the accuracy of the data base by additional work, such as failure modes and effects analyses, or with additional data from designers, manufacturers, and users.

Jerome Weiss, Project Manager

Advanced Power Systems Division 
CONTENTS

Section

1 INTRODUCTION

Background

$1-1$

Project scope

$1-2$

Project objectives

$1-2$

Report Organization

$1-3$

2

TECHNICAL APPROACH

2-1

Overview of the Approach

$2-1$

Task 1: Characterize Plant Design and Equipment

$2-2$

Task 2: Construct Fault Trees for the System

$2-3$

Task 3: Collect Data and Develop a Data Base

$2-5$

Task 4: Adapt and Apply the RAM Model

$2-6$

Task 5: Develop and Incorporate Reliability Growth Estimates

$2-7$

Task 6: Prepare Final Report

$2-8$

Plant Design Description

$2-8$

ISS1: Brine/Hydrocarbon Heat Exchangers

$2-8$

ISS2: Turbine/Generator set

$2-10$

ISS3: Hydrocarbon Condensers and Accumulators

$2-10$

ISS4: Hydrocarbon Circulatioi Pumps

$2-10$

ISS5: Cooling Tower Fan Modules

2-11

ISS6: Circulating water Pumps

$2-11$

ISS7: Brine Reinjection Booster Pumps

$2-11$

Fault Trees and system states

$2-11$

Assessment Model Description

$2-14$

Data Base

$2-17$

Electric Power Utilities

$2-17$

Petroleum Refining Companies

$2-17$

Bromine Manufacturers

$2-18$

Electric Power Associations

$2-18$

Turbine Designer and Manufacturer

$2-18$ 
Preliminary Design (Baseline) Assessment

Sensitivity Analyses and Component Rankings 


\section{ILIUSTRATIONS}

\section{Figure}

Page

2-1 Flow Diagram of Heber Assessment Tasks

2-2 Heber Plant Partitioning

$2-9$

2-3 Examples of Fault-Tree Structures

$2-12$

2-4 General Flow Diagram of the Heber Program

3-1 A Comparison of Inherent Reliability (Effectiveness) vs. Time for the Heber Plant and EXTC-GCC Plant

3-2 Heber Baseline Reliability and Availability Assessment Results

3-3 Subsystem Sensitivity Analysis

$3-8$

3-4 Reliability Growth Scenario

3-5 Cumulative Effects of Reliability Growth on Steady-State Effectiveness

A-1 Fault Tree: ISSl - Brine/Hydrocarbon Heat Exchangers

$\mathrm{A}-3$

A-2 Fault Tree: ISS2 - ISS2 Turbine/Generator

A -4

A-3 Fault Tree: ISS3 - Hydrocarbon Condenser/Accumulator

$\mathrm{A}-5$

A-4 Fault Tree: ISS4 - Hydrocarbon Circulation Pumps

$A-6$

A-5 Fault Tree: ISS5 - Cooling Tower Fan Modules

$\mathrm{A}-7$

A-6 Fault Tree: ISS6 - Circulating water Pumps

A-8

A-7 Fault Tree: ISS7 - Brine Reinjection Booster Pump

A-9

C-1 Heber Flow Chart

$\mathrm{C}-3$

$\mathrm{C}-2$ Heber Program Listing 


\section{TABLES}

Table

2-1 Heber System-State Definitions

3-1 Failure and Repair Data

3-2 Environmental Stress Data

3-3 Summary of Steady-State Availabilities

3-4 Heber Component Rankings

3-5 Potential Reliability Improvement Candidates

3-6 Estimated Changes in Subsystem Availability and Plant Effectiveness Attributed to Reliability Growth

B-1 Heber Component Data Sources

C-1 Program Variables
Page

2-13

$3-2$

$3-3$

3-7

$3-10$

3-11

$3-12$

$\mathrm{B}-3$

$\mathrm{C}-11$ 
SUMMARY

The assessment methodology employed in this study was developed under EPRI Contract RP 1461 and adapted for use in the reliability and availability assessment of the Heber Geothermal Plant. It had also been previously used to analyze gasification combined-cycle (GCC) and advanced coal-fired plant (CFP) designs, as well as a number of operational oil-fired and gas-fired combined-cycle plants. EPRI contracted with ARINC Research Corporation (1) to adapt its assessment methodology to the Heber binary cycle design so that initial baseline estimates of the plant reliability and availability could be obtained, and (2) to develop an operating model that could be used in evaluating design alternatives and obtaining updated assessments of the expected plant performance as the design evolves.

The specific objectives of the project are as follows:

- To develop a computer-based reliability and availability assessment model of the Heber design

- To exercise the model to obtain baseline estimates of the plant reliability and availability

- To determine the sensitivity of the baseline results to data uncertainties

- To rank the plant components by their effect on the baseline results

- To identify potential availability improvement options

- To assess the impact of potential reliability growth on the plant's performance

The assessment model was based on the design illustrated in the Preliminary Design Manual for a Geothermal Demonstration Plant at Heber, California, EPRI ER-670, February 1978. This design uses the binary cycle to develop $45 \mathrm{MW}_{\mathrm{e}}$ of output power from the moderate temperature brine of the Heber geothermal reservoir. It is recognized that the final design may differ significantly and that subsequent iterations of the assessment may be desirable. 
The study consisted of the following interrelated tasks:

- Characterize the plant design and equipment

- Define system states, fault trees, and state definitions

- Develop component failure and repair data base

- Adapt and apply the assessment model

- Develop reliability growth estimates and assess their impact

- Prepare final report

On the basis of the preliminary design, the plant was partitioned into seven independent subsystems (ISSS). A fault tree (described in section 2 of this report) was developed for each subsystem to relate the occurrence of a top-level event (e.g., subsystem failure) to the individual components within the subsystem that could cause the event. Probability expressions were then developed for each subsystem type, based on fault trees and available data, which represent the probabilities of the top-level events as a function of the constituent component failure and repaix characteristics.

System states and their associated capabilities were defined in terms of the operational conditions of the seven identified ISSs. Twenty-five system states and their associated availabilities were defined with the assistance of the Ben Holt Company. The individual subsystem expressions were then used, in conjunction with the state definitions, to define probability expressions that represent the likelihood of moving from each defined state to each other possible state, or remaining in the same state in a given short interval of time. This resulted in a 25-by-25 matrix of expressions, called the transition matrix, which was used in the assessment model. A component failure and repair data base was then developed. For a number of unavoidable reasons, this data base consisted of extrapolations of available data combined with estimates by consensus from the knowledgeable personnel in the organizations contacted.

A program designed for interactive time-share computer application was developed to determine the reliability and availability assessments and to perform sensitivity analyses. Baseline reliability and availability assessments were made by using the acquired data base, and component rankings were developed following sensitivity analyses. Finally, components with potential reliability growth were identified; a timephased scenario of the growth was hypothesized; and the program containing data for the improved components was used to produce an estimate of the potential availability growth with time. 
Baseline evaluations of reliability and availability were obtained by using the data base and by exercising the assessment model. One measure of inherent reliability (the time for the plant to decrease from 100 percent to 50 percent expected capacity in the absence of corrective maintenance) was 37.5 days. Comparable values obtained from assessments of GCC and CFP designs were about nine days and eight days, respectively. Similarly, the availability assessment was found to approach a steady-state value of about 81 percent. The corresponding GCC and CFP availability measure values were 79 percent and 82 percent, respectively. The most likely state is the "all up" state (State 1), with an availability of 34.2 percent. Further, the probability of at least 75 percent capacity is 0.71 and the probability of a full outage is approximately 0.02. Finally, it was determined from the results of the baseline assessment that the probability of 100 percent capacity for five days was 0.885 and the probability of at least 75 percent capacity for 60 days was 0.725 .

Sensitivity analyses were performed to determine the effect that changes in the baseline data would have on the resultant steady-state effectiveness (availability measure) value. Component rankings were developed in accordance with the following criteria:

- Power Lost -- the increase in steady-state effectiveness when a component is considered to be perfect (i.e., it is assumed to be failurefree).

- Availability -- the change in steady-state effectiveness per change in component availability.

- Failure Rate -- the change in steady-state effectiveness per change in component failure rate.

- Mean Time to Restore -- the change in steady-state effectiveness per change in component mean time to restore.

The resultant rankings indicate that the heat exchanger represents the most sensitive component, whereas the circulating water pump and motor have a comparatively negligible impact.

As a part of the baseline data-collection effort, potential areas of reliability improvement were investigated and source estimates of expected growth were obtained. It was determined that potential growth opportunities existed for six "if the seven subsystems. Implementation of the identified improvements, coupled with reliability growth estimates by the sources, would increase the steady-state effectiveness by about nine percent over a ten-year period. In addition, further growth could be achieved by introducing bypass capabilities in the heat exchanger and the 
condenser/accumulator subsystems. This, for example, would permit operation of the plant in additional higher-capacity states when a failure occurs in a heat exchanger rather than losing the entire subsystem and dropping to 50 percent capacity.

Evaluation of the Heber design, using the baseline data, produced reliability and availability estimates that were equal to or better than previously evaluated GCC and CFP designs. The heat exchanger has the greatest impact on the avai1ability measure. An additional nine percent growth in availability could be realized through a combination of expected component reliability growth and the improvements resulting from the implementation of several design changes. 
Section 1

INTRODUCTION

This report presents the results of a six-month investigation of the expected reliability and availability of the proposed Heber Geothermal Binary Demonstration Plant. The investigation was conducted by ARINC Research Corporation for the Electric Power Research Institute (EPRI) as part of EPRI Research Project 1900. Contract RP 1900-2 was administered under the technical direction of both Mr. Jerome Weiss of EPRI's Advanced Power Systems Division and Mr. Vasel Roberts, EPRI Heber Project Manager.

\section{BACKGROUND}

In 1976 EPRI initiated feasibility studies of the Heber Geothermal Binary Demonstration Plant project. The primary purpose of the project was to accelerate geothermal development for electric powex generation in the United states by developing a power conversion system having high-resource-utilization efficiency for a moderate temperature, low salinity, hydrothermal power plant. This project was to demonstrate power conversion technology, environmental control technology, and the economics of power generation. A second objective was to estabiish the binary cycle technology as a proven alternative to the flash steam cycle for those applications in which reservoir characteristics and site specific considerations make closed-loop systems more desirable. The documentation of technical studies, analyses, and evaluations, and the dissemination of that information were also considered important objectives.

The plant is to be located at the Heber geothermal field in the Imperial Valley of southern California. Its design is based on a binary fluid conversion cycle wherein a saturated hydrocarbon is utilized as the secondary working fluid. The primary geothermal fluid (brine) will be supplied from an adjacent production facility. The hot brine will be delivered to the power plant boundary in the saturated liquid phase. Following the transfer of heat energy from the geothermal fluid to the hydrocarbon working fluid in heat exchangers, the brine will be returned for injection into the Heber reservoir. The hydrocarbon will vaporize in the heat exchangers and then drive a turbine/generator to produce electrical energy. 
The preliminary design work that was undertaken following the feasibility study and completed in 1977 formed the basis for this analysis. Because of funding difficulties the project was dormant from 1978 to 1980, at which time the detailed design effort was resumed. This analysis, based on the earlier preliminary design effort, was undertaken to develop inputs to the detailed design effort as a part of a reliability and availability enhancement program for the project. It is likely that the final design may differ significantly from the preliminary design and that subsequent iterations of the analysis may be desirable.

\section{PROJECT SCOPE}

The reliability and availability assessments in this project were developed on the basis of preliminary design data and the best failure and repair data that were available during the period of the contract. Both EPRI project management and ARINC Research recognized that this early assessment might lack precision but would provide an insight into potential problem areas that might be corrected as a result of timely identification. This project included identifying and obtaining sufficient data and performance measures so that it would be possible to make an adaptation and application of a reliability and availability assessment model, which was previously developed for EPRI for application to other power plants. In the absence of specific data, expert opinion from knowledgeable sources was to be used in performing the baseline assessments and in estimating possible areas for reliability growth.

\section{PROJECT OBJECTIVES}

The specific objectives of the project are as follows:

- To perform initial reliability and availability assessments of the Heber plant design

- To identify and rank components of the Heber plant in order of their criticality to system operation and their contribution to system unavailability

- To determine the sensitivity of the plant availability to data uncertainties

- To recommend changes to the design to improve the plant's reliability and availability

- To predict the effects of reliability growth of components on plant performance

This project was intended to provide an early insight into the reliability and availability characteristics of the proposed Heber geothermal plant. The predictions that resulted from the analysis are not precise, because a statistically valid data base 
is not yet available. The analyses were expected to provide reasonable values and uncertainties associated with those values, sensitivities of results to uncertainties in the data, identification of critical components and their impact on reliability and availability, a guide to future data needs and recommendations for improving the data base, and recommendations for improving system reliability and availability. The data collection and development effort was also expected to result in a preliminary data base that would be as consistent as possible and that could be expanded and improved as field data become available.

\section{REPORT ORGANIZATION}

Section 2 of this report describes the project tasks and subtasks, including an overview of the technical approach, the design of the plant; fault tree analyses and modeling methods; and the efforts involved in data collection. Section 3 describes the data base, the underlying assumptions used in the analysis, and the results of the assessments performed. These results include a baseline set of results as determined from the present design and data, an assessment of potential reliability growth, and the impact of this growth. In section 4 , the results are interpreted, conclusions are described, and recommendations are presented. Appendixes A through D present the fault trees developed for the preliminary design, sources for the data base used in the analysis, the computer program used in the analysis, and the mathematical expressions used in ranking the components in order of their criticality to plant performance. 
Section 2

TECHNICAL APPROACH

This section presents an overview of the technical approach and a description of the tasks required to perform this project. In addition, a description of the plant design, the subsystem fault trees and system state definitions, and the adaptation of the reliability, availability, and maintainability (RAM) analysis model are also presented. This section concludes with a general discussion of data collection efforts.

OVERVIEW OF THE APPROACH

The project, as illustrated in Figure 2-1, consisted of six interrelated tasks:

- Task 1: Characterize the Plant Design and Equipment (Configuration)

- Task 2: Construct Fault Trees for the system

- Task 3: Collect Data and Develop a Data Base

- Task 4: Adapt and Apply the RAM Model

- Task 5: Develop and Incorporate Reliability Growth Estimates

- Task 6: Prepare Final Report

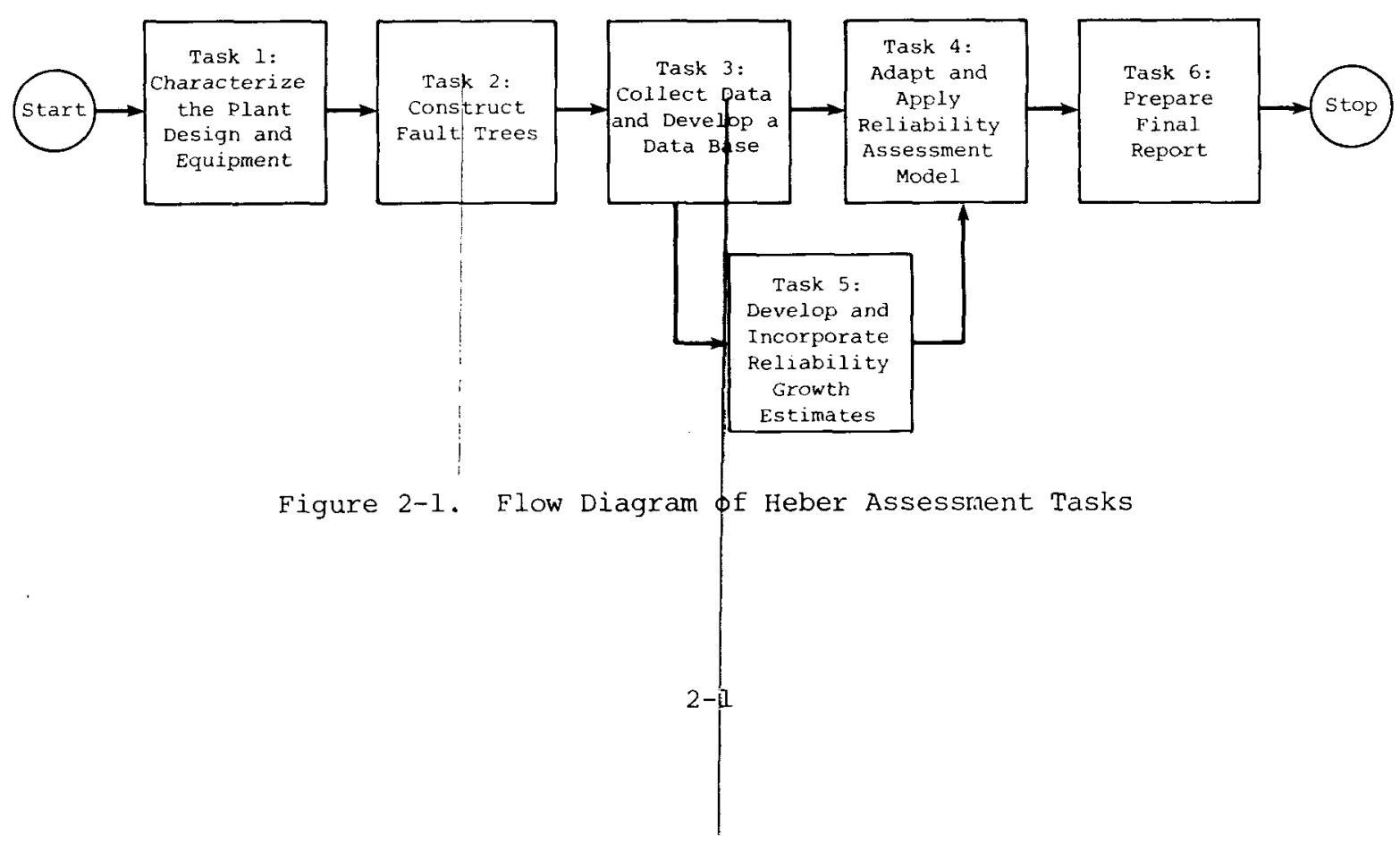


Both EPRI and contractor assistance were required to characterize and describe the proposed plant and to obtain usable data. The plant design, described in later paragraphs of this section, was used as the baseline for the assessment. It was recognized that the design would be changing during the course of this project but, because of the limited period of performance, it was necessary to select a baseline assumption at the outset. Fault tree construction, system state and capacity definitions, and the adaptation and application of the RAM model all followed the general experience of earlier* EPRI work. Estimating and assessing the impact of reliability growth and improvements was based on a knowledge of probable failure modes and causes, those measures which might be applicable to mitigate their effects, and assistance from expert sources contacted. Each of the tasks and their associated subtasks are discussed in greater detail in the following paragraphs.

Task 1: Characterize Plant Design and Equipment

The objectives of Task 1 were to characterize the plant design and its equipment, to partition the plant design into independent subsystems, and to define the system states and related capabilities. To accomplish these objectives, this task was divided into the following major subtasks:

- Subtask 1A: Obtain and Review Plant Design and Equipment Data

- Subtask 1B: Partition the Plant Design into Independent Subsystems

- Subtask 1C: Determine the Number of System States and Their Associated Capabilities

Subtask 1A: Obtain and Review Plant Design and Equipment. The review was based on EPRI Report ER-670, Preliminary Design Manual for a Geothermal Demonstration Plant at Heber, California, Topical Report on Project 580, Holt/Procon, February 1978. This design and equipment description was subsequently supplemented by discussions with some of the contractors identified in Appendix B and by EPRI Report ER-1099, Heber Geothermal Demonstration Power Plant, Final Report on Project 580-2, Fluor Engineers and Constructors, Inc., June 1979. The review consisted primarily of developing an understanding of the equipment in terms of types of use, service, and functional characteristics. These were necessary steps to permit application of the first step in the analysis method -- the partitioning of the system into independent subsystems.

*EPRI AP-1610, Guide for the Assessment of the Reliability of Gasification-CombinedCycle Power Plant, ARINC Research Corporation, November 1980, and EPRI AP-1643, Development of a Reliability Prediction Methodology for a Gasification-CombinedCycle Power Plant, ARINC Research Corporation, November 1980. 
Subtask 1B: Partition the Plant Design into Independent Subsystems. The method for partitioning the plant into independent subsystems is described in detail under "Plant Design Description" (page 2-8). In general, the approach is to partition the plant equipment into groups of identical equipments that perform a distinct and separate function in the process. For purposes of the analysis and to fit the RAM model structure, these groups are assumed to be independent subsystems. This partitioning then permits the identification of the number of possible, nonambiguous states that the system may assume in operation and permits a corresponding capacity for each system state to be identified. Subtask lB followed a methodology described in detail in EPRI Report AP-1610.

Subtask 1C: Determine the Number of System states and Their Associated Capabilities. Each independent subsystem was assumed to have a linear relationship to total plant capacity based on information supplied by the system designer and EPRI. Each independent subsystem (hereinafter called ISS) was considered to be either operating or nonoperating, with no partially operating states permitted except where the ISS contained a number of identical components in parallel. The number of possible nonambiguous states in combination for all of the ISSs were then tabulated. For each state identified, a corresponding plant power output was determined. This effort is discussed under "Fault Trees and System states" of this section.

Task 2: Construct Fault Trees for the System

A fault tree is a graphic representation that depicts the relationship of events that may occur to a system and its components. Fault trees were developed for each ISS to relate the occurrence of top-level events and events that contribute to each top-level event. This analysis divided each ISS into components that contributed to a top-level event -- either a failure or a repair. The "tree" structure is carried out until there are insufficient data to assign failure or repair times to each block of the tree. This analysis then permits the development of mathematical expressions of failure and repair probability. These probabilistic expressions are the algorithms used in the computer program to determine the relationship of transitions from one state to another state as components and subsystems fail and are repaired. Task 2 subtasks are described in the following paragraphs.

Subtask 2A: Identify Top-Level Events and the Major Components for Each ISS. The failure or repair of each ISS is the top-level event of interest. In identifying the major components of each ISS, the contribution of each component to the top-level event is determined. For example, if an ISS consists of three major components any one of which can fail the ISS, the top-level event occurs if any of the three 
Lower order events occur (see Appendix A). However, if the ISS operates unabated with only two of the three major components operating, the top-level event cannot occur until both major components fail. Identification of the events and components is necessary for the construction of fault trees.

Subtask 2B: Develop Fault Trees. The ISS Fault trees comprise the components of each subsystem type in the ISS. These fault trees illustrate the relationship of all of the components to the ISS. This subtask aids in identifying the level to which the analysis can be taken. In general, the more detailed the fault tree, the more accurate the analysis. Since failure and repair times are associated with each block in the tree, data limitations will restrict the detail of the fault trees. It is theoretically possible to generate extremely complex and detailed fault trees; however, if supporting data for each block are not available, then these details are of little value. It can be assumed that the failure and repair rates assigned to each block of the tree account for all the failures and repairs that could occur at all lower levels. This assumption both simplifies the analysis and indicates an area for improvement when limited data are available. The fault trees are employed to obtain probabilistic expressions of top-level events (either failure or repair) in terms of reliability and maintainability functions. These expressions are then incorporated into the model.

Subtask 2C: Develop State Transition Probability Expressions. All significant system states were identified and described by first defining State 1 as the condition in which all subsystems are operating. Then, each subsystem of each ISS is considered to fail in turn or to remain operating to define the subsequent degraded states. When all the possible combinations were exhausted, i.e., all possible states defined, these states were then related to plant capability -- the estimates of power output in each state. These state definitions were used as elements of the transition expressions and were then entered into the structure of the model.

In this case, the model is a structured representation of the plant that employs a mathematical rather than a graphical presentation. To compute the probabilities of various component groupings, the model uses numerical data derived from component failure and repair rates. It depicts the actual operation of the plant as a continuous process in which the plant passes from one state to another, subject to the probabilities involved. The probabilities define the likelihood of the plant moving from one state to another (e.g., from state 1 to state 2, given that it started in state 1) and are contained in the state-transition matrix, the dimensions of which are the number of possible system states. 
When the model is exercised, plant output can vary both up and down. The statetransition matrix contains the probabilities associated with the plant changing from one state to another. In notation form, the various transition probabilities are represented by $(T)$ and subscripted to indicate the beginning and ending states. Thus $T_{1,1}$ is the probability of the plant's remaining in state 1 during a specific time interval, while $\mathrm{T}_{1,2}$ is the probability of the plant's beginning a specific time interval in state 1 and beginning the next time interval in state 2. Specific expressions were developed for the probability of the system's moving from every possible state to every other state.

\section{Task 3: Collect Data and Develop a Data Base}

The objectives of Task 3 were to identify the components for which failure and repair data were needed and the possible sources of these data, and to collect the available data. Given data from all available sources and estimates of missing (but needed) data, these data were then used as the basis for estimates of failure and repair measures necessary to the operation of the RAM assessment model. Task 3 was divided into three subtasks:

- Subtask 3A: Identify Data Requirements and Sources

- Subtask 3B: Acquire and Assess Available Data

- Subtask 3C: Develop Failure and Repair Estimates

Each of these subtasks is described in the following paragraphs.

Subtask 3A: Identify Data Requirements and Sources. The fault tree graphic representations determined the components for which data were desired. In addition, the previously cited Heber Design Manual defined the boundary conditions of operation. Standard industry, utility, and manufacturing sources were contacted, as well as EPRI and several architect-engineer organizations. Generally, data were not readily available as discussed in subsequent paragraphs of this section. Data sources who provided information used in the study are listed in Appendix $B$ of this report.

Subtask 3B: Acquire and Assess Available Data. Data for major components of the type to be used in the proposed Heber design were not readily available. Data were available for some similar components that could be extrapolated for the Heber application. Where no data were available but were necessary to the analysis, some estimates from knowledgeable personnel were solicited for use. This absence 
of data for advanced technology designs was expected. To understand the impact of uncertainties in data, sensitivity analyses were performed, as described in the discussion of subtask $4 \mathrm{C}$ (page 2-7).

Subtask 3C: Develop Failure and Repair Estimates. Data requested from manufacturers, designers, EPRI, and appropriate national organizations were reviewed and assessed. Failure and repair estimates for each major ISS component were either derived from data estimates by knowledgeable personnel or from available operating experience data. The resulting estimates of failure and repair rates were assigned to each applicable block of the ISS fault trees for use in the computer program. The fault tree levels of detail exceeded the availability of data or estimates such that the desired level of detail was not achieved. However, the level used was sufficient to the analysis.

Task 4: Adapt and Apply the RAM Model

The reliability, availability, and maintainability (RAM) assessment model employed is an adaptation of the effectiveness model first used on EPRI Project RP 1461 and cițed in the GCC Plant Guide (EPRI AP-1610). In addition to adapting the model to the specifics of the Heber design, the model was also used to assess the impact of reliability growth. Task 4 is divided into the following three subtasks:

- Subtask 4A: Modify the Assessment Program

- Subtask 4B: Exercise the Model to Obtain a Baseline Assessment

- Subtask 4C: Perform Sensitivity and Component Criticality Analyses

Each of the subtasks are described in the following paragraphs.

Subtask 4A: Modify the Assessment Program. The RAM assessment program first described in EPRI Report AP-1610 is constructed in a series of modules. Adaptation of the program required direct substitution of the state transition matrix, the capability matrix, and the transition probability data of the Heber design into the modular framework of the Markov chain computer program. The modified computer program is listed in Appendix $C$ of this report.

Subtask 4B: Exercise the Model to Obtain a Baseline Assessment. Exercising the model yielded an estimate of the inherent reliability of the plant based on the best data estimates for each ISS and major component employed in the analysis. A time-varying analysis to determine a measure of availability was also performed. Further discussion of these efforts is provided under "Assessment Model Description" 
of this section (page 2-14). The baseline assessment was used both as an aid in analyzing reliability growth and as an assessment of the plant's performance as configured in the preliminary design. The baseline can then be used as a basis for comparison in determining component sensitivity, criticality, and reliability growth potential.

Subtask 4C: Perform Sensitivity and Component Criticality Analyses. For each time interval in the baseline run, the model sums the contribution of each of the possible states toward the total plant capacity. From the description of the plant partitioning and the determination of system states, it can be seen that these states are related to the probability of failure and repair of each Iss and the components within the ISS. To determine sensitivity to uncertainty and to changes in the data, the availability of each ISS was varied in turn, while the remaining ISSs were held at baseline. This procedure provides an indication of the extent to which the results are sensitive to the availability of each ISS, i.e., the sensitivity of the results to uncertainties in the data. This can be illustrated graphically by a plot of the deviation of plant availability from the baseline contributed by each ISS. Steep slopes indicate greater sensitivity to data uncertainties. Therefore, if the slope is shallow, there is little need to obtain better data. Steeper slopes indicate the need for testing, design improvements, or intensified data acquisition programs. Examples of the results of this analysis are presented in section 3 .

The issue of criticality is addressed in a similar manner. Each ISS availability is held perfect in turn (100 percent available) while the remainder stay at baseline to assess the impact on plant capacity or availability. Those components having the greatest change are most critical to overall plant performance.

Task 5: Develop and Incorporate Reliability Growth Estimates

Experience dictates that the acquisition of new systems or the development of advanced technology result in early life problems that are corrected in time. These corrections produce an improvement in plant reliability and availability, which is equivalent to the concept of reliability growth. In Task 5, analysis of the plant design and component criticality identified those components which probably could be improved. Estimates were prepared to indicate the potential problem areas and appropriate corrective actions. These are discussed in greater detail in section 3 , (pages 3-9 through 3-16) of this report. These analyses resulted in a revised set of failure and repair rates and a time-phased scenario, which were exercised in the computer program and then compared with the baseline. 


\section{Task 6: Prepare Final Report}

The effort and results of each task are presented in this final report. The fault trees, computer program, and failure and repair sources are provided in appendixes to this report. In addition to discussions of the implication of the analyses, underlying assumptions in conducting this project have been identified wherever they are appropriate to understand the approach, methods, or results.

\section{PLANT DESIGN DESCRIPTION}

The Heber Geothermal Demonstration Plant uses the binary cycle to generate electric power. Basically, the binary cycle uses two working fluids:

- The primary working fluid is the geothermal brine.

- The secondary working fluid is the hydrocarbon mixture of 80 percent isobutane and 20 percent isopentane.

The primary working fluid transfers its thermal energy to the secondary working fluid, which in turn serves to drive a turbine/generator set to produce electric power.

The plant can be divided into seven independent subsystems (ISSs), and their functions are linked to generate power from the geothermal brine. The ISSs and their functions are described in the following paragraphs. Figure 2-2 illustrates the partitioning of the plant for this project.

\section{ISSI: Brine/Hydrocarbon Heat Exchangers}

ISSl is a series/parallel-connected train of two sets of four shell and tube heat exchangers. Each stage in the heat exchanger is directly connected to the succeeding stage to provide for a balanced flow, with no design provision for isolation or bypass of these stages. As shown in Figure 2-2, hot brine enters the fourth stage and leaves the first stage to be returned to the geothermal anomaly. The hydrocarbon working fluid enters the first stage and leaves the fourth stage to enter the curbine/generator set. Because of the design constraints, the failure of any single stage will fail 50 percent of the ISS. This failure also has the effect of reducing plant power output capacity by 50 percent.

It should be noted that because of temperature losses in the geothermal reservoir with time, an additional heat exchanger is planned for installation at approximately the midpoint of expected plant life to maintain net plant power output. 


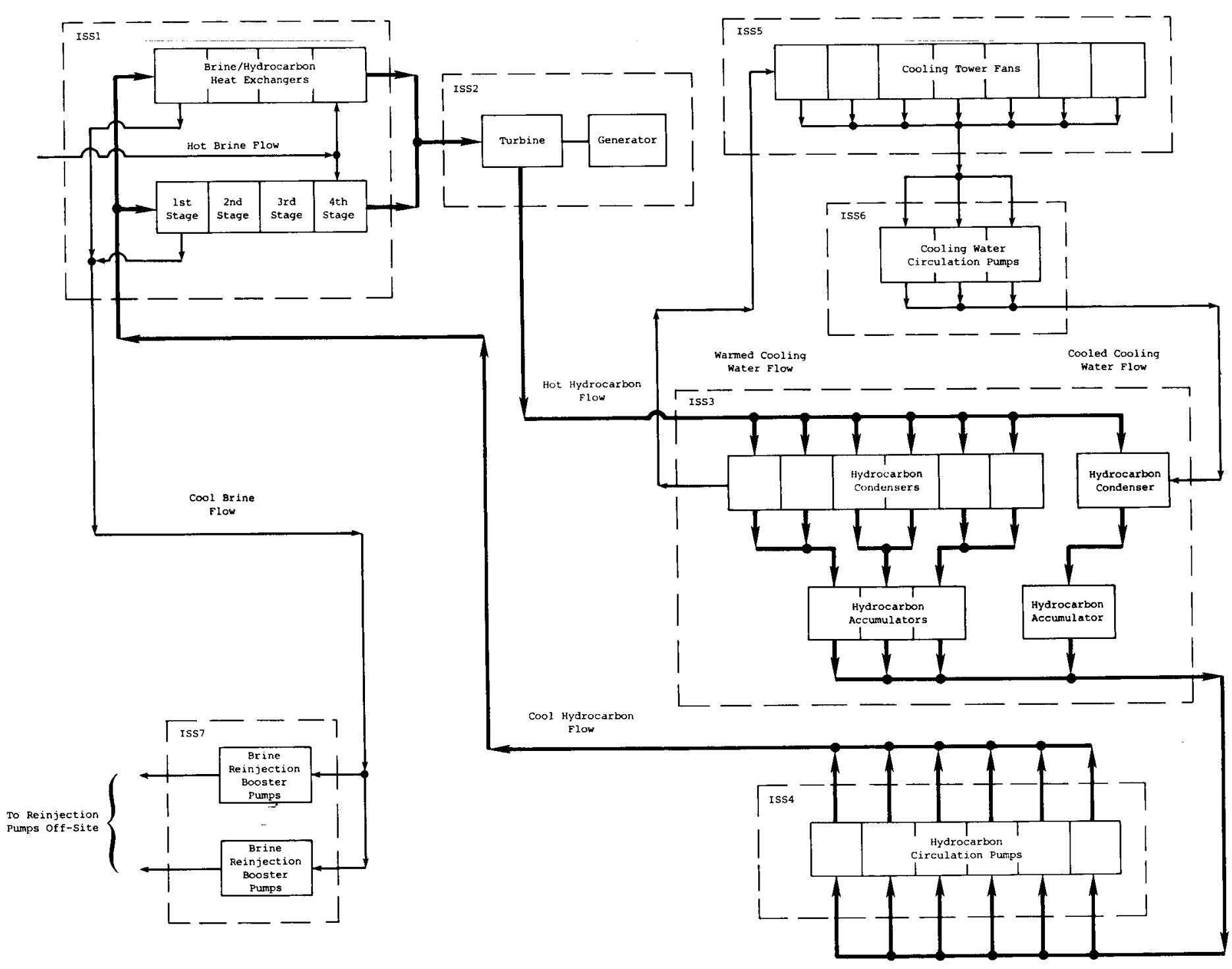

Figure 2-2. Heber Plant Partitioning 
The impact of this change is not assessed herein, since it was not part of the baseline design.

ISS2: Turbine/Generator set

A $65 \mathrm{MW}_{\in}$ turbine that expands the hot hydrocarbon vapors from the heat exchanger and produces a net output of $45 \mathrm{MW}_{\mathrm{e}}$ will be provided. The hydrocarbon vapors leave the turbine and are cooled through a set of condensers that are part of ISS3. A failure of either the turbine or the generator reduces plant power output to zero.

\section{ISS3: Hydrocarbon Condensers and Accumulators}

The hydrocarbon condensers and accumulators are arranged in three sets of two condensers and one accumulator and a fourth set of one condenser and one accumulator. Another condenser will be added to this last accumulator in the future when the geothermal anomaly undergoes thermal degradation, because more brine and hydrocarbon will be used to compensate for the temperature loss. At the direction of EPRI management, this additional condenser was included in the analysis.

The condensers receive the hot hydrocarbon vapors from the turbine exhaust; these vapors are cooled back to a liquid by passing over tubes that contain circulating cooling water. The accumulators function as containment vessels for the hyarocarbons, which are then piped to the hydrocarbon circulation pumps.

The valving and piping design of ISS3 is such that the failure of either a condenser or an accumulator removes the entire set from service. In this analysis, loss of a condenser and accumulator set reduced plant power by approximately 25 percent.

ISS/: Hydrocarbon Circulation Pumps

ISS4 is arranged in a parallel bank of six pump and motor combinations. The configuration provides for complete isolation of any one of the pumps in the ISS. The pump system is the primary source of flow for the working hydrocarbon fluid of the plant. Failure of either a motor or a pump removes that set from service with a corresponding power loss of approximately 16.6 percent. A seventh set is planned for future installation when the geothermal anomaly undergoes thermal degradation. This set is not included in the analysis. 
ISS5: Cooling Tower Fan Modules

ISS5 consists of seven fan modules, each of which contains a fan and motor set. Cooling water is used in the hydrocarbon condensers (ISS3) and is pumped back to the cooling tower by the circulating water pumps (ISS6). The gravity flow through each of the seven modules is cooled by the fan pulling ambient air across the water cascade. Water is cooled below ambient air temperature, collected in the basin, treated, and pumped back to the system. The loss of any one of the modules, caused by the loss of either a fan or a motor, would result in a loss of approximately 14.3 percent cooling capability. As the anomaly degrades thermally, three additional modules will be installed to compensate for the increased hydrocarbon in the system required for thermal stability. These three modules were not addressed in the analysis.

\section{ISS6: Circulating Water Pumps}

ISS6 consists of three sets of pumps and motors, only two of which normally operate. The capacity of each is 50 percent of the total requirement. The third set is a normally inoperative spare. The loss of a single set, either pump or motor, has no effect on capacity; however, the loss of two sets reduces capacity by 50 percent. The loss of all three sets reduces output capacity to zero.

\section{ISS7: Brine Reinjection Booster Pumps}

The brine reinjection booster pumps are used for returning the cooled brine to the geothermal anomaly for reheating. The subsystem consists of two sets of pumps and motors. The geological pressures that exist in the anomaly will have a direct bearing on the size and capacity of these pumps. If a pump were to fail, the plant's capacity would be reduced by 50 percent, because of the inability to move the requisite amounts of heated brine through the plant.

\section{FAULT TREES AND SYSTEM STATES}

Fault trees are produced by an iterative process that should be used when a plant of any complexity is being analyzed. Structurally, each fault tree consists of a top-level event and a series of subsidiary events whose occurrence could produce the top-level event. Generally, these events can occur in two ways, defined by the use of either an AND gate, represented by $\bigcirc$, or an oR gate, represented by $\curvearrowright$.

If an AND gate is present, all of the subsidiary events feeding into the gate must occur to bring about the top-level event. Thus, for example, if the failure of a particular pump can bring about the designated top-level event and if this pump is in parallel with another pump of the same type, size, and function, an AND gate 
will be used to represent this configuration. The presence of an AND gate indicates that both the operating pump and the spare pump must fail before the top-level event can occur. If an OR gate is used in the tree, the occurrence of any of the events or the failure of any of the components directly connected to the gate will bring about the top-level event. These symbols, with their integration into simple trees, are illustrated in Figure 2-3. (Reference to a more detailed treatment of fault trees will indicate that there are many more faulttree symbols than are shown here.) Although a more elaborate symbology could be required in some cases, the $O R$ gate is the only relationship that was needed in analyzing the Heber configuration. That is, the failure of any one of the components in an ISS would cause a failure of that ISS. A complete set of fault trees for the Heber plant is presented in Appendix A. These trees were employed to write probabilistic expressions for failure and repair events for use in the model.

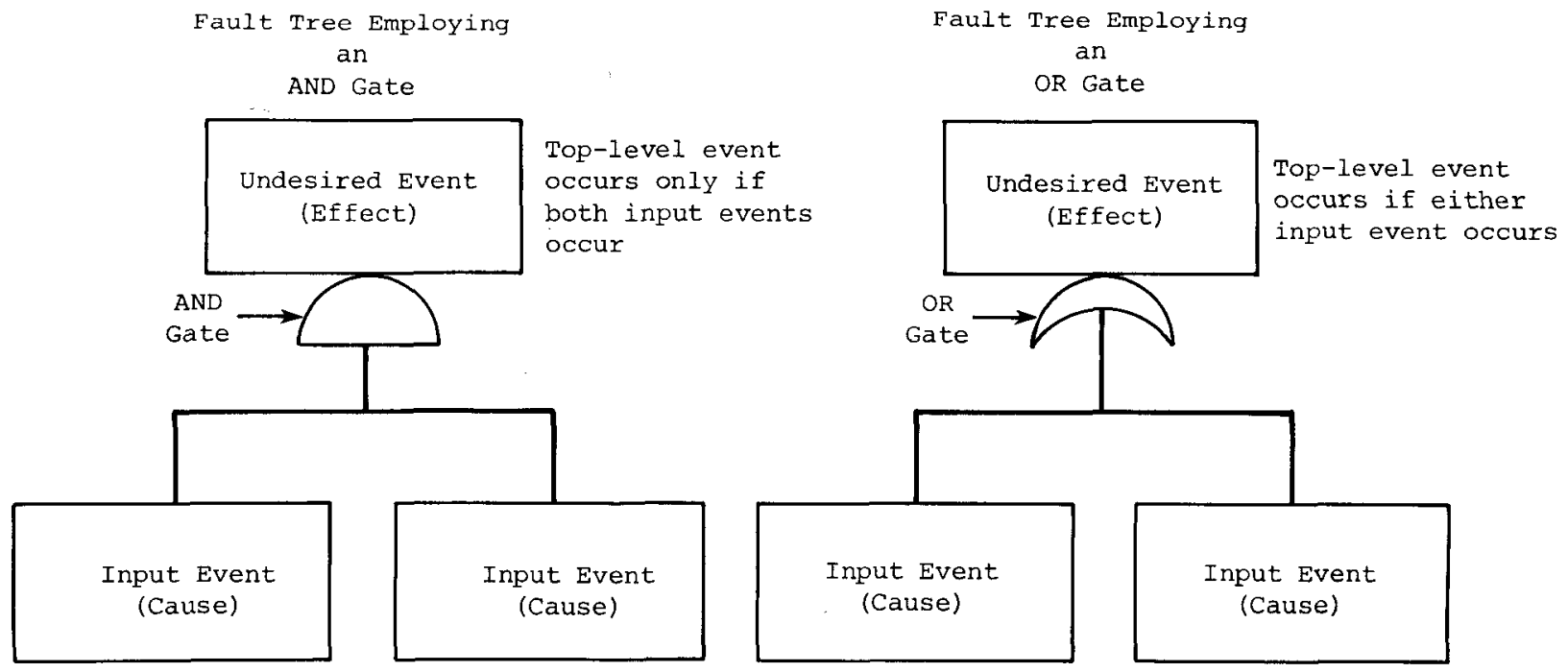

Figure 2-3. Examples of Fault-Tree Structures

The system capabilities were determined on the basis of the assumption that the output of each subsystem, or loss of output, was a linear relationship between capacity and the number of identical ISSs.* For example, the loss of a single hydrocarbon circulation pump (ISS4) would reduce the capability of the plant to handle the requisite amount of secondary working fluid by approximately one-sixth.

*Letter from the Ben Holt Company to Mr. J. M. White, Jr., dated March 18, 1981, regarding linearity of plant capacity and failed ISS. 
Twenty-five nonambiguous system states were defined for the Heber Plant; their associated capacities are presented in Table 2-1. The numbers in parentheses in each ISS column heading represent the quantity of similar subsystems present in each ISS group. A zero in any column indicates that there are no failed subsystems in that ISS in the given state (all operating). Any other number indicates the number of failed subsystems of that ISS, which assists in defining the state of the entire Heber plant. For example, in State 3, all subsystems of ISS1, ISS2, ISS3, and ISS7 are operating, while ISS4 has one failed subsystem and ISS5 and ISS6 are defined as having less than two $(<2)$, either zero or one, failed subsystems. The resulting plant capacity in State 3 is 83 percent of the full rated output.

Table 2-1

HEBER SYSTEM-STATE DEFINITIONS

\begin{tabular}{|c|c|c|c|c|c|c|c|c|}
\hline State & $\begin{array}{c}\text { ISS } 1 \\
(2)\end{array}$ & $\begin{array}{c}\text { ISS2 } \\
\text { (1) }\end{array}$ & $\begin{array}{c}\text { ISS3 } \\
(4)\end{array}$ & $\begin{array}{c}\text { ISS4 } \\
(6)\end{array}$ & $\begin{array}{c}\text { ISS5 } \\
(7)\end{array}$ & $\begin{array}{l}\text { ISS6 } \\
(2+1)\end{array}$ & $\begin{array}{c}\text { ISS7 } \\
(2)\end{array}$ & $\begin{array}{c}\text { Percentage } \\
\text { of Maximum } \\
\text { Capacity }\end{array}$ \\
\hline 1 & 0 & 0 & 0 & 0 & 0 & $<2$ & 0 & 100 \\
\hline 2 & 0 & 0 & 0 & 0 & 1 & $<2$ & 0 & 86 \\
\hline 3 & 0 & 0 & 0 & 1 & $<2$ & $<2$ & 0 & 83 \\
\hline 4 & 0 & 0 & $I$ & $<2$ & $<2$ & $<2$ & 0 & 75 \\
\hline 5 & 0 & 0 & $<2$ & $<2$ & 2 & $<2$ & 0 & 72 \\
\hline 6 & 0 & 0 & $<2$ & 2 & $<3$ & $<2$ & 0 & 67 \\
\hline 7 & 0 & 0 & $<2$ & $<3$ & 3 & $<2$ & 0 & 58 \\
\hline 8 & 1 & 0 & $<2$ & $<3$ & $<4$ & $<2$ & 0 & 50 \\
\hline 9 & $<2$ & 0 & 2 & $<3$ & $<4$ & $<2$ & O & 50 \\
\hline 10 & $<2$ & 0 & $<3$ & 3 & $<4$ & $<2$ & 0 & 50 \\
\hline 11 & $<2$ & 0 & $<3$ & $<4$ & $<4$ & 2 & 0 & 50 \\
\hline 12 & $<2$ & 0 & $<3$ & $<4$ & $<4$ & $<3$ & 1 & 50 \\
\hline 13 & $<2$ & 0 & $<3$ & $<4$ & 4 & $<3$ & $<2$ & 43 \\
\hline 14 & $<2$ & 0 & $<3$ & 4 & $<5$ & $<3$ & $<2$ & 33 \\
\hline 15 & $<2$ & 0 & $<3$ & $<5$ & 5 & $<3$ & $<2$ & 29 \\
\hline 16 & $<2$ & 0 & 3 & $<5$ & $<6$ & $<3$ & $<2$ & 25 \\
\hline 17 & $<2$ & 0 & $<4$ & 5 & $<6$ & $<3$ & $<2$ & 17 \\
\hline 18 & $<2$ & 0 & $<4$ & $<6$ & 6 & $<3$ & $<2$ & 15 \\
\hline 19 & 2 & $<2$ & $<5$ & $<7$ & $<8$ & $<4$ & $<3$ & 0 \\
\hline 20 & $<2$ & 1 & $<5$ & $<7$ & $<8$ & $<4$ & $<3$ & 0 \\
\hline 21 & $<2$ & 0 & 4 & $<7$ & $<8$ & $<4$ & $<3$ & 0 \\
\hline 22 & $<2$ & 0 & $<4$ & 6 & $<8$ & $<4$ & $<3$ & 0 \\
\hline 23 & $<2$ & 0 & $<4$ & $<6$ & 7 & $<4$ & $<3$ & 0 \\
\hline 24 & $<2$ & 0 & $<4$ & $<6$ & $<7$ & 3 & $<3$ & 0 \\
\hline 25 & $<2$ & 0 & $<4$ & $<6$ & $<7$ & $<3$ & 2 & 0 \\
\hline
\end{tabular}




\section{ASSESSMENT MODEL DESCRIPTION}

The Heber plant, like other advanced power-generation plants, is a reasonably complex system capable of operating over a number of states, ranging from full capacity to no capacity. To represent these conditions adequately in assessing plant reliability and availability, a system's effectiveness approach was employed. As mentioned earlier, this approach was initially developed and applied to a gasification-combinedcycle power plant. The following definitions were employed in the assessment of the Heber plant using this methodology:

- Reliability Measure. The expected* time for the plant to reach an a priori defined level of effectiveness in the absence of corrective maintenance, given that the plant was initially in a completely "up" condition. (For this analysis a 50 percent level of effectiveness was used.) This time represents a measure of the inherent reliability of the plant design.

- Availability Measure. The steady-state** effectiveness value when corrective maintenance is included.

- Effectiveness. The sum of the weighted contribution of each possible system state to the plant's output capacity. It can be expressed as an absolute (e.g., megawatts) or as a percentage of maximum capacity, and it represents an averaging over the possible system states or expected value for the plant. Further, since the likelihood of being in each particular state will vary with time, effectiveness will be a time-dependent quantity that will approach zero if repair is not permitted, and it will approach a finite steady-state value when repair is permitted.

The effectiveness function is determined by a Markov analysis and is defined for the interval $(t, t+\Delta)$ by the following matrix products:

$$
E(t, t+\Delta)=A(t) T(t, t+\Delta t) C
$$

where the matrices are defined as follows:

- $A(t)$ is a row matrix, called the availability matrix, whose elements $A_{i}(t)$ are the probabilities that the system is in each of its possible states at time $t$. If there are $\mathrm{N}_{\mathbf{s}}$ possible states, then

$$
\sum_{i=1}^{N_{S}} A_{i}(t)=1
$$

for all values of $t$. Initially, i.e., at $t=0, A(0)=(1,0, \ldots 0)$ or in other words, the system is in an "all up" condition with zero probability of being in a state of degraded capability.

\footnotetext{
*"Expected" is used with respect to an average value. Although no specific unit would operate in precisely this way, the average of all units should.

**Steady state is equivalent to the average over a long period of time.
} 
- $T(t, t+\Delta t)$ is a square matrix $\left(N_{S} \times N_{S}\right)$, called the transition matrix, whose elements $\left(T_{i j}\right)$ are the probabilities of the system's transitioning from state $i$ to state $j$ during the interval $(t, t+\Delta t)$. These probabilities are defined by the constituent subsystem reliability and maintainability probability expressions and the state definitions. The time interval, $\Delta t$, is made sufficiently small so that the probability of multiple events occurring during the interval is negligibly small. Further, when corrective maintenance is not permitted (i.e., for the reliability assessment), all elements of the transition matrix containing repair events are set to zero.

- $\quad C$ is a column matrix having $\mathrm{N}_{S}$ elements, called the capability matrix. Each element $\left(C_{j}\right)$ represents the capacity of the plant when it is in state $i$. For the Heber analysis, the capacity of each state was expressed as a percentage of the maximum capacity.

Figure 2-4 is a flow diagram of the computer program employed in the analysis. Appendix $\mathrm{C}$ presents a detailed description and program listing.

Inputs to the program, which has been configured for use on a CDC time-share system, include component data entry and a set of responses to inquiries. The required responses are the type of run (reliability or availability), the time interval (in hours) between sets of calculations, and the number of iterations (complete time intervals) to be calculated.

A 12-hour time interval was selected for the Heber design, because it was estimated to be an interval in which the probability of more than one state change was very small. However, the interval was still large enough to preserve computer efficiency.

After the failure and repair parameters for each component in each ISS and the appropriate inquiry responses are entered, the program reads the data file and calculates each ISS reliability and maintainability measure from the component parameters and the fault tree logic. The availability and transition matrices are updated to account for state changes. Substate* availabilities are updated and the availability of each ISS is subsequently updated. Finally, the expected effectiveness of the entire plant is updated for each iteration of the program. program results are then printed.

Printed results of the program are the effectiveness (or equivalent operational availability) of the plant for each of the intervals selected and the availability associated with each state in the last interval. The data may then be varied to test for sensitivity or criticality by selecting the additional run option.

*This update is required for those states defined by an Iss entry having a "less than" number (e.g., <2) entry. 


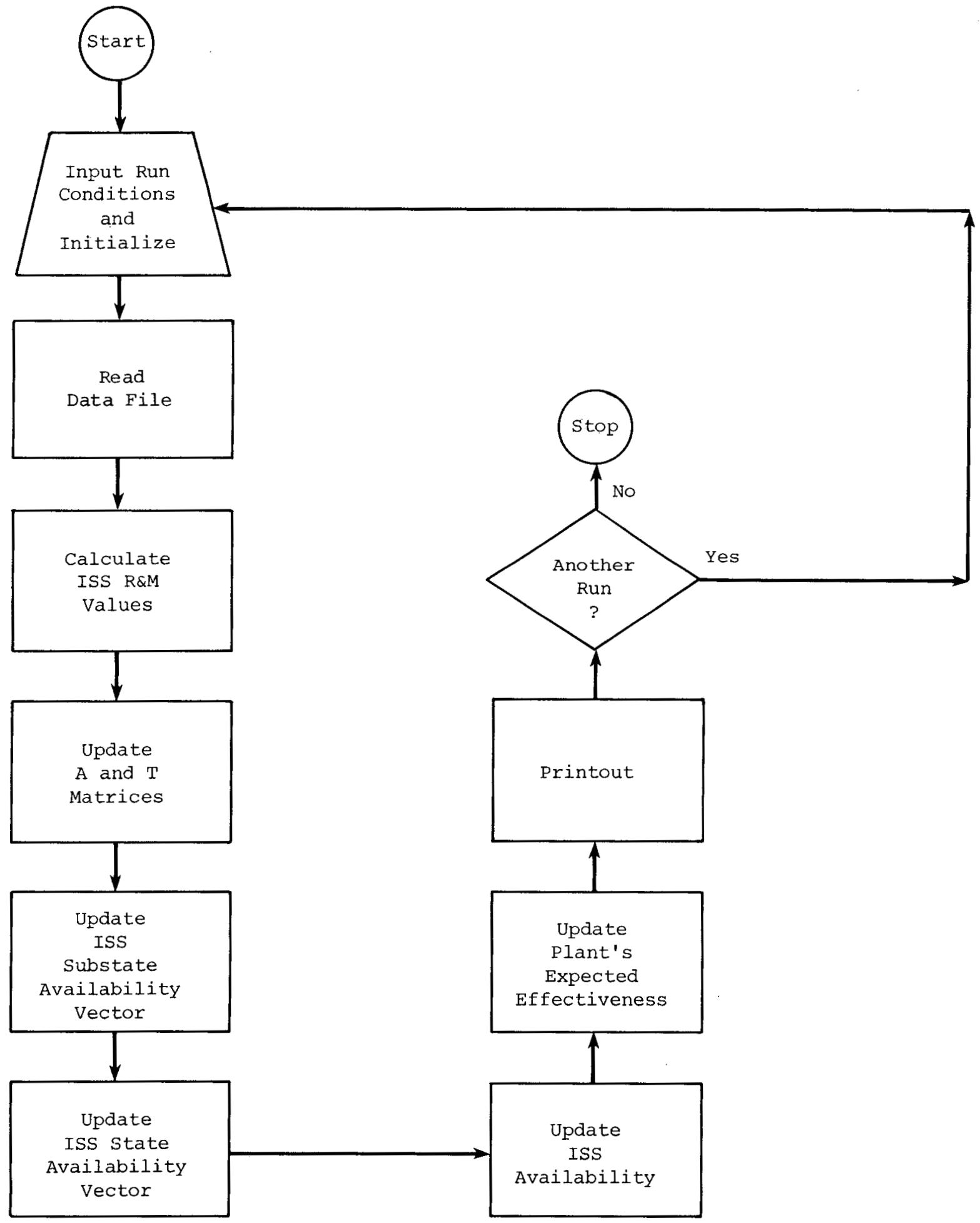

Figure 2-4. General Flow Diagram of the Heber Program 
DATA BASE

The search for component and subsystem reliability, maintainability, and performance data required contacting numerous potential sources. The following industries and associations agreed to provide information for the study:

- Two electric power utilities

- Two petroleum refining companies

- Two bromine manufacturers

- Two electric power associations - the National Electric Reliability Council and the Edison Electric Institute

- A turbine manufacturer

- The architect-engineer responsible for the preliminary design of the Heber plant

Although other potential sources were contacted, data either were nonexistent or were not disclosed for proprietary reasons. Because of the lack of similar systems in service, the value of this proprietary data may be limited even if it were available. Data results are presented in Section 3. Appendix B lists the specific sources who provided information used in the study. Results of these efforts are discussed in the following paragraphs.

\section{Electric Power Utilities}

The two electric power utilities agreed to provide data on those components in cooling tower fan modules (ISS5) and circulating water pumps (ISS6). The utility personnel contacted included central engineering office representatives and site operations and maintenance personnel. In general, data for circulating water pumps and cooling tower fan modules were representative of the Heber design and were believed to be representative of industry experience.

\section{Petroleum Refining Companies}

Two petroleum refining companies provided operational information on turbines (ISS2), hydrocarbon condensers and accumulators (ISS3), and hydrocarbon circulation pumps (ISS4). The central engineering offices and two operating sites were contacted for their operation and maintenance experience with these equipments. Neither had experience with turbines of the size to be used at Heber, but they did offer opinions on similar designs believed to be representative of the larger unit. Hydrocarbon condensers and accumulators are standard refinery equipment and, with the correct choice of materials to match the type of service, perform satisfactorily 
for a number of operating years. The hydrocarbon circulation pumps at Heber are 2,000 brake horsepower (bhp), whereas the largest that either of the two refineries had was 1,200 bhp. Their operating experience with this pump was excellent, and the refiners believed that 2,000 bhp should give nearly equivalent service with proper maintenance and steady-state operation. In their opinion, the data for the smaller unit could be extrapolated and applied to the larger units.

\section{Bromine Manufacturers}

Two bromine manufacturers were contacted for the operation and maintenance histories of tleir brine heat exchangers (ISSI), spent brine reinjection booster pumps (ISS7), and their associated components. The operating histories of heat exchangers, using hot brine as one of the working fluids, indicate that they are subject to frequent failures during operation. The users of the heat exchangers stated that the choice of materials used in fabrication is a critical factor. The size and capacity of the reinjection pumps is related to the "downhole" pressure of the anomaly; i.e., if the pressure is minimal, then smaller pumps can be used. Normal operating procedures require that the pumps run in a steady-state mode. Steadystate operation has produced acceptable performance histories for this industry. These data and the estimates were considered to be directly applicable to the Heber plant.

\section{Electric Power Associations}

Both the Edison Electric Institute (EEI) and the National Electric Reliability Council (NERC) were contacted for information on the operating histories of turbines and generators (ISS2) in the $65 \mathrm{MW}$ output range. The NERC ten-year data on units of this size were reviewed for outage and repair histories. Both the failure and repair statistics were used in this project. This data base included 48 systems and 95 units, for a total of 458 unit-years.

\section{Turbine Designer and Manufacturer}

The designer and manufacturer of the axial flow design turbine, or hydrocarbon expander (part of ISS2), was requested to provide test, performance, and repair statistics on the design. No quantitative data were available; however, other information useful to this project was available, including estimates by the manufacturer that correlated well with the opinions of hydrocarbon expander experts at the petroleum refining companies. 
Section 3

ANALYSIS RESULTS

This section presents the results of the analyses and investigations conducted for the Heber project. In addition to presenting the data base used in the analyses, this section describes the baseline assessment of the Heber Geothermal Demonstration Plant preliminary design and also the impact of reliability growth. The results of the preliminary design analysis, or baseline case, consist of reliability and availability assessments, a sensitivity analysis, and a ranking of the various components on the basis of their impact on overall plant performance. Details of these results are presented in the following paragraphs.

DATA BASE

The component failure and repair data base for the Heber Geothermal Demonstration Binary Plant was assembled with the cooperation of the organizations listed in Appendix B, subject to the constraints discussed in Section 2. However, a number of problems were encountered in developing this data base, primarily because of the virtual nonexistence of histories on like components. A limited quantity of data were available on similar equipments (e.g., for different sizes or capacities of equipment or equipment operating in a different environment). These data were extrapolated* to conform to the physical, operational, and environmental requirements of the Heber design. Data available for use were at a higher level of indenture than either planned or desirable. An examination of the fault trees in Appendix $A$ indicates the desired level for component data. However, data used, or data capable of being estimated by knowledgeable sources, were at a higher component level. Finally, many of the sources contacted either did not collect this type of information or, if they did, would not release it for proprietary reasons.

Data used in the analysis are presented in Table 3-1. Table 3-2 lists the environmental conditions under which the data are applied. In examining this data base, it should be noted that only ISS2, ISS5, and ISS6 are based on histories of like components. The remaining component data were derived from a combination of extrapolations of similar equipment data and data estimates of knowledgeable

*The method used to extrapolate data was based on best estimates obtained from discussions with knowledgeable designers and users of the equipment. 
Table 3-1

FAILURE AND REPAIR DATA

\begin{tabular}{|c|c|c|c|c|c|}
\hline \multirow[b]{2}{*}{ ISS } & \multirow{2}{*}{$\begin{array}{l}\text { Subsystem or } \\
\text { Component }\end{array}$} & \multicolumn{2}{|c|}{ Components } & \multicolumn{2}{|c|}{ Subsystem } \\
\hline & & $\begin{array}{c}\text { MTBF } \\
\text { (Hours) }\end{array}$ & $\begin{array}{c}\text { MTTR } \\
\text { (Hours) }\end{array}$ & $\begin{array}{c}\text { MTBF } \\
\text { (Hours) }\end{array}$ & $\begin{array}{c}\text { MTTR } \\
\text { (Hours) }\end{array}$ \\
\hline 1 & $\begin{array}{l}\text { Brine/Hydrocarbon } \\
\text { Heat Exchangers }\end{array}$ & & & 1,980 & 168 \\
\hline 2 & Turbine/Generator & & & 16,545 & 307 \\
\hline & Turbine & 25,820 & 370 & -- & -- \\
\hline & Generator & 46,445 & 193 & -- & -- \\
\hline 3 & $\begin{array}{l}\text { Hydrocarbon } \\
\text { Condensers/ } \\
\text { Accumulators }\end{array}$ & & & 19,147 & 316 \\
\hline & $\begin{array}{l}\text { Condenser } \\
\text { Accumulator }\end{array}$ & $\begin{array}{r}43,560 \\
158,400\end{array}$ & $\begin{array}{l}366 \\
168\end{array}$ & -- & -- \\
\hline 4 & $\begin{array}{l}\text { Hydrocarbon } \\
\text { Circulation } \\
\text { Pumps }\end{array}$ & & & 6,592 & 168 \\
\hline & $\begin{array}{l}\text { Pump } \\
\text { Motor }\end{array}$ & $\begin{array}{r}7,920 \\
39,300\end{array}$ & $\begin{array}{l}168 \\
168\end{array}$ & -- & -- \\
\hline 5 & $\begin{array}{l}\text { Cooling Tower } \\
\text { Fan Modules }\end{array}$ & & & 7,011 & 710 \\
\hline & $\begin{array}{l}\text { Fan } \\
\text { Motor }\end{array}$ & $\begin{array}{l}15,840 \\
12,575\end{array}$ & $\begin{array}{r}1,512 \\
72\end{array}$ & -- & -- \\
\hline 6 & $\begin{array}{l}\text { Circulating } \\
\text { Water Pumps }\end{array}$ & & & 210,900 & 57 \\
\hline & $\begin{array}{l}\text { Pump } \\
\text { Notor }\end{array}$ & $\begin{array}{r}1,265,398 \\
253,080\end{array}$ & $\begin{array}{r}100 \\
48\end{array}$ & -- & -- \\
\hline 7 & $\begin{array}{l}\text { Brine Reinjection } \\
\text { Booster Pumps }\end{array}$ & & & 9,900 & 48 \\
\hline
\end{tabular}

personnel. Independent subsystem data were calculated by using the combined availabilities of components to determine their measures of reliability and maintainability.

\section{PRELIMINARY DESIGN (BASELINE) ASSESSMENT}

The following paragraphs present the results of the baseline assessment, including an assessment of the reliability and availability of the preliminary design, an 


\begin{tabular}{|c|c|c|c|}
\hline & \multicolumn{3}{|c|}{$\begin{array}{c}\text { Table } 3-2 \\
\text { ENVIRONMENTAL STRESS DATA }\end{array}$} \\
\hline & \multirow{2}{*}{$\begin{array}{l}\text { Subsystem or } \\
\text { Component }\end{array}$} & \multicolumn{2}{|c|}{ Environmental Conditions } \\
\hline & & Design Data & Operating Data \\
\hline 1 & $\begin{array}{l}\text { Brine/Hydrocarbon } \\
\text { Heat Exchangers } \\
\text { Tube (Brine) Side } \\
\text { Shell (Hydrocarbon) } \\
\text { Side }\end{array}$ & $\begin{array}{l}360^{\circ} \mathrm{F}, 180 \mathrm{psig} \\
360^{\circ} \mathrm{F}, 67 \mathrm{psig}\end{array}$ & $\begin{array}{l}109^{\circ}-295^{\circ} \mathrm{F}, 138 \text { psig } \\
360^{\circ}-153^{\circ} \mathrm{F}, 535 \text { psig }\end{array}$ \\
\hline 2 & $\begin{array}{l}\text { Turbine/Generator } \\
\text { Turbine } \\
\text { Generator }\end{array}$ & $\begin{array}{ll}360^{\circ} \mathrm{F}, & 650 \mathrm{psia} \\
13,800 \text { Vac }\end{array}$ & $295^{\circ} \mathrm{F}, 500 \mathrm{psia}$ \\
\hline 3 & $\begin{array}{l}\text { Hydrocarbon Condenser/ } \\
\text { Accumulator } \\
\text { Condenser } \\
\text { Shell } \\
\text { Tube } \\
\text { Accumulator }\end{array}$ & $\begin{array}{l}450^{\circ} \mathrm{F}, 165 \mathrm{psig} \\
450^{\circ} \mathrm{F}, 100 \mathrm{psig} \\
450^{\circ} \mathrm{F}, 165 \mathrm{psig}\end{array}$ & $\begin{array}{l}104^{\circ}-166^{\circ} \mathrm{F}, 58 \mathrm{psig} \\
90^{\circ}-108^{\circ} \mathrm{F}, 30 \mathrm{psig} \\
104^{\circ} \mathrm{F}, 56 \mathrm{psig}\end{array}$ \\
\hline 4 & $\begin{array}{l}\text { Hydrocarbon Circulation } \\
\text { Pumps } \\
\text { Pump } \\
\text { Motor }\end{array}$ & $\begin{array}{l}104^{\circ} \mathrm{F}, 4,707 \mathrm{gpm} \\
1,800 \mathrm{rpm}, 2,000 \mathrm{hp}\end{array}$ & $104^{\circ} \mathrm{F}, 4,707 \mathrm{gpm}$ \\
\hline 5 & $\begin{array}{l}\text { Cooling Tower Fan } \\
\text { Modules }\end{array}$ & $95^{\circ} \mathrm{F}, 140,000 \mathrm{gpm}$ & $90^{\circ}-108.7^{\circ} \mathrm{F}, 137,085 \mathrm{gpm}$ \\
\hline 6 & $\begin{array}{l}\text { Circulating Water Pumps } \\
\text { Pump } \\
\text { Motor }\end{array}$ & $\begin{array}{l}90^{\circ} \mathrm{F}, 68,543 \mathrm{gpm} \\
585 \mathrm{rpm}, 2,000 \mathrm{hp}\end{array}$ & $\begin{array}{l}-- \\
--\end{array}$ \\
\hline 7 & $\begin{array}{l}\text { Brine Reinjection } \\
\text { Booster Pump }\end{array}$ & -- & $160^{\circ} \mathrm{F}, 300 \mathrm{psig}$ \\
\hline
\end{tabular}

analysis of the sensitivity of the availability assessment to uncertainties in the data, and an analysis of the criticality of major components to the performance of the plant. 


\section{Reliability Assessment}

The analysis model was exercised for a total of 200 iterations (12-hour periods), or 100 days, to assess the inherent operating reliability of the plant. In this type of analysis, the plant is assumed to start operating in an "all up" condition and is permitted to run while failures occur in accordance with the parametric failure rates identified. However, repairs are inhibited so that no corrective (or planned) maintenance is permitted. The run is terminated when the plant decays from 100 percent expected capacity to 50 percent of that capacity. The 50 percent limit is chosen arbitrarily and has no resemblance to real operations: This type of analysis does, however, provide an insight into the reliability of the components in the plant and provides a measure of the plant's inherent reliability. The time for the Heber plant to decay to the 50 percent level was approximately 37.5 days (75 twelve-hour intervals). This value may be compared with that of a previously analyzed coal gasification-combined-cycle (GCC) power plant and a large coal combustion power plant; their inherent reliability values were nine days and eight days, respectively. A comparison of the Heber plant and the theoretical GCC plant (identified as EXTC) is illustrated in Figure 3-1. The comparison shows that the inherent reliability of components in the Heber design may be as much as four times more reliable than those selected for the EXTC GCC power plant.

\section{Availability Assessment}

The availability assessment approach differs from that for the inherent reliability in that repairs are permitted, thereby enabling the plant to have both upward and downward state transitions. In this analysis, the computer program runs through a series of iterations until the plant performance decays to its steady limit, i.e., the point at which failures and repairs reach virtual equilibrium. The baseline case steady-state effectiveness closely approximates an equivalent operating availability for the plant.* The steady-state effectiveness for the plant was calculated to be 80.5 percent and is shown in Figure 3-2. This value was reached at approximately 2,136 hours, or 89 days.

The reliability assessment results are also shown for comparison. The coal-fired plant corresponding availability values were 81.6 percent and the EXTC GCC plant was 79.4 percent. The steady-state availabilities for each of the defined system states are presented in Table 3-3. It can be seen from the table that the most likely state is the "all up" state (State 1), with an availability of 34.2 percent. *If scheduled maintenance were included in the analysis, then the steady-state effectiveness would be analogous to the NERC definition of equivalent availability. 


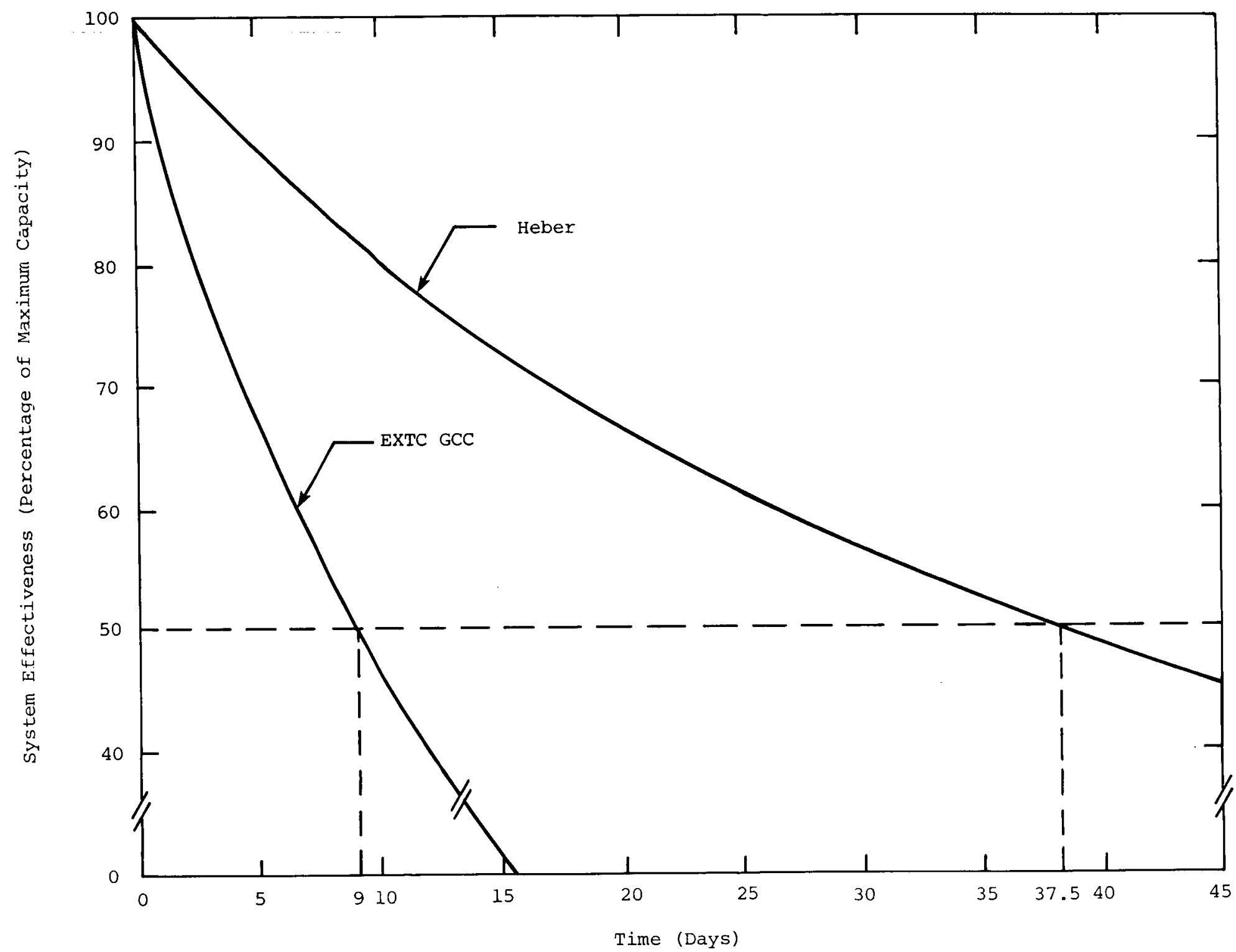

Figure 3-1. A Comparison of Inherent Reliability (Effectiveness) vs. Time for the Heber Plant and EXTC GCC Plant 


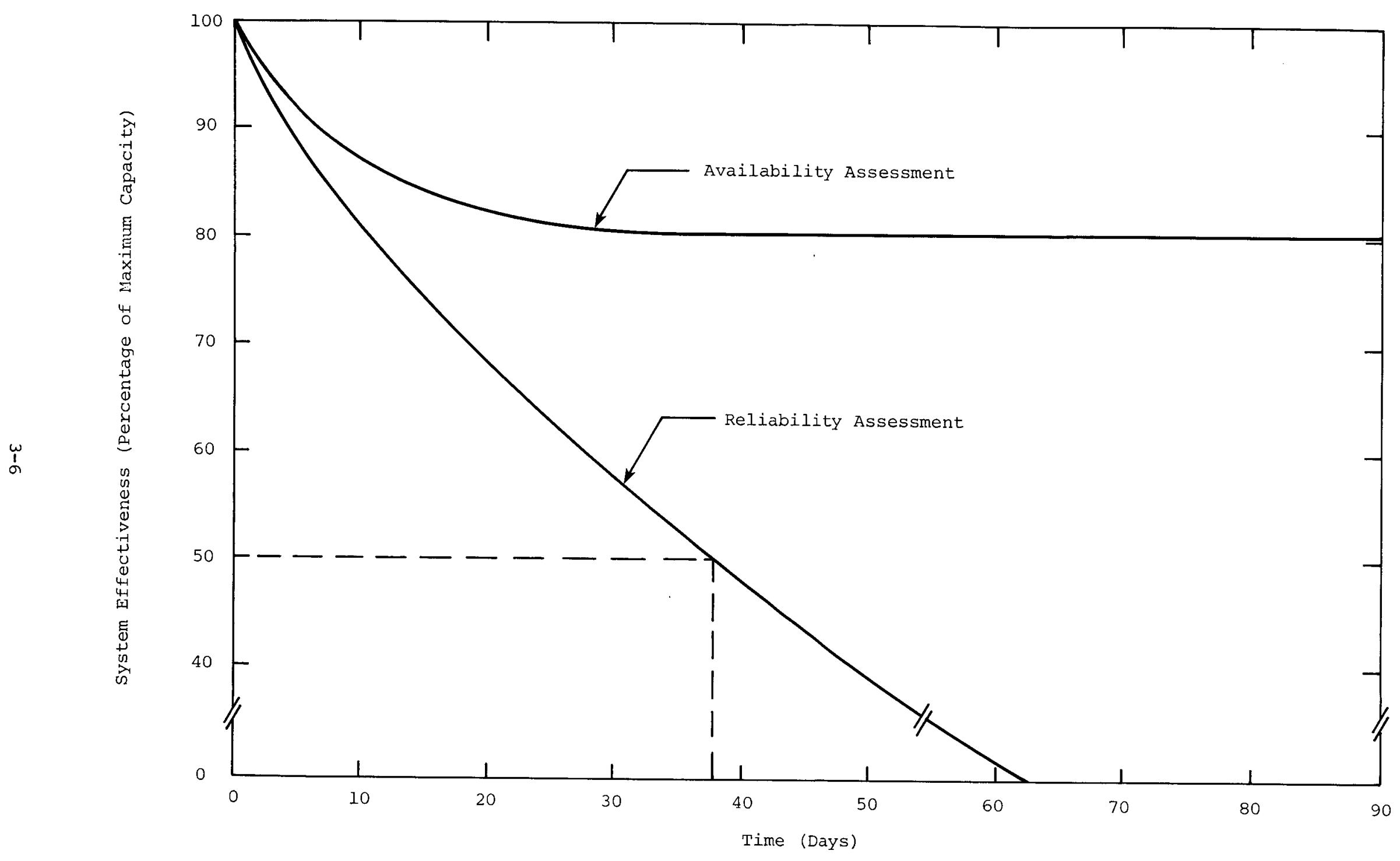

Figure 3-2. Heber Baseline Reliability and Availability Assessment Results 


\begin{tabular}{|c|c|c|}
\hline \multicolumn{3}{|c|}{$\begin{array}{c}\text { Table } 3-3 \\
\text { SUMMARY OF STEADY-STATE } \\
\text { AVAILABILITIES }\end{array}$} \\
\hline State & $\begin{array}{c}\text { Percentage } \\
\text { of } \\
\text { Capacity }\end{array}$ & $\begin{array}{c}\text { Percentage } \\
\text { of } \\
\text { Availability }\end{array}$ \\
\hline $\begin{array}{r}1 \\
2 \\
3 \\
4 \\
5 \\
6 \\
7 \\
8 \\
9 \\
10 \\
11 \\
12 \\
13 \\
14 \\
15 \\
16 \\
17 \\
18 \\
19 \\
20 \\
21 \\
22 \\
23 \\
24 \\
25\end{array}$ & $\begin{array}{r}100 \\
86 \\
83 \\
75 \\
72 \\
67 \\
58 \\
50 \\
50 \\
50 \\
50 \\
50 \\
43 \\
33 \\
29 \\
25 \\
17 \\
15 \\
0 \\
0 \\
0 \\
0 \\
0 \\
0 \\
0\end{array}$ & $\begin{array}{r}34.2 \\
23.7 \\
8.6 \\
4.5 \\
8.7 \\
0.6 \\
1.4 \\
14.4 \\
0.1 \\
<0.1 \\
<0.1 \\
1.0 \\
0.2 \\
<0.1 \\
<0.1 \\
<0.1 \\
<0.1 \\
<0.1 \\
0.6 \\
1.8 \\
<0.1 \\
<0.1 \\
<0.1 \\
<0.1 \\
<0.1\end{array}$ \\
\hline
\end{tabular}

Further, it can be seen that the probability of at least 75 percent capacity (the sum of availabilities for states having 75 percent capacity and above) is 71 percent and that the probability of a full outage (zero capacity) is approximately 2.5 percent. Finally, it was determined from the baseline assessment results that the probability of 100 percent capacity for five days was 0.885 and the probability of at least 75 percent capacity for 60 days was 0.725 .

\section{Sensitivity Analyses and Component Rankings}

Sensitivity analyses were performed to determine the impact of uncertainties in the data base on baseline results. The impact on steady-state effectiveness is compared with variations in the availability of each of the major subsystems. The ISS 
availabilities were varied, as shown in Figure 3-3, to demonstrate the effects of uncertainties in the component data. The figure indicates that the dominant subsystem is the brine/hydrocarbon heat exchanger (ISSl) by a narrow margin, with turbine/generator (ISS2) and cooling tower fan modules (ISS5) closely following. The shallow slopes of the remaining subsystems indicate relative insensitivity to data uncertainties, because of their limited effect on baseline steady-state availability.

In assessing the sensitivity to data uncertainties, Figure 3-3 illustrates that a change in the availability of the cooling tower fan modules (ISS5) from the baseline 90 percent to a hypothetical 80 percent, for example, could decrease the steady-state effectiveness measure to approximately 0.73. It is unlikely that data are that inaccurate, since such a change could be produced only by a large reduction in MTBF, an even larger increase in MTTR, or both.

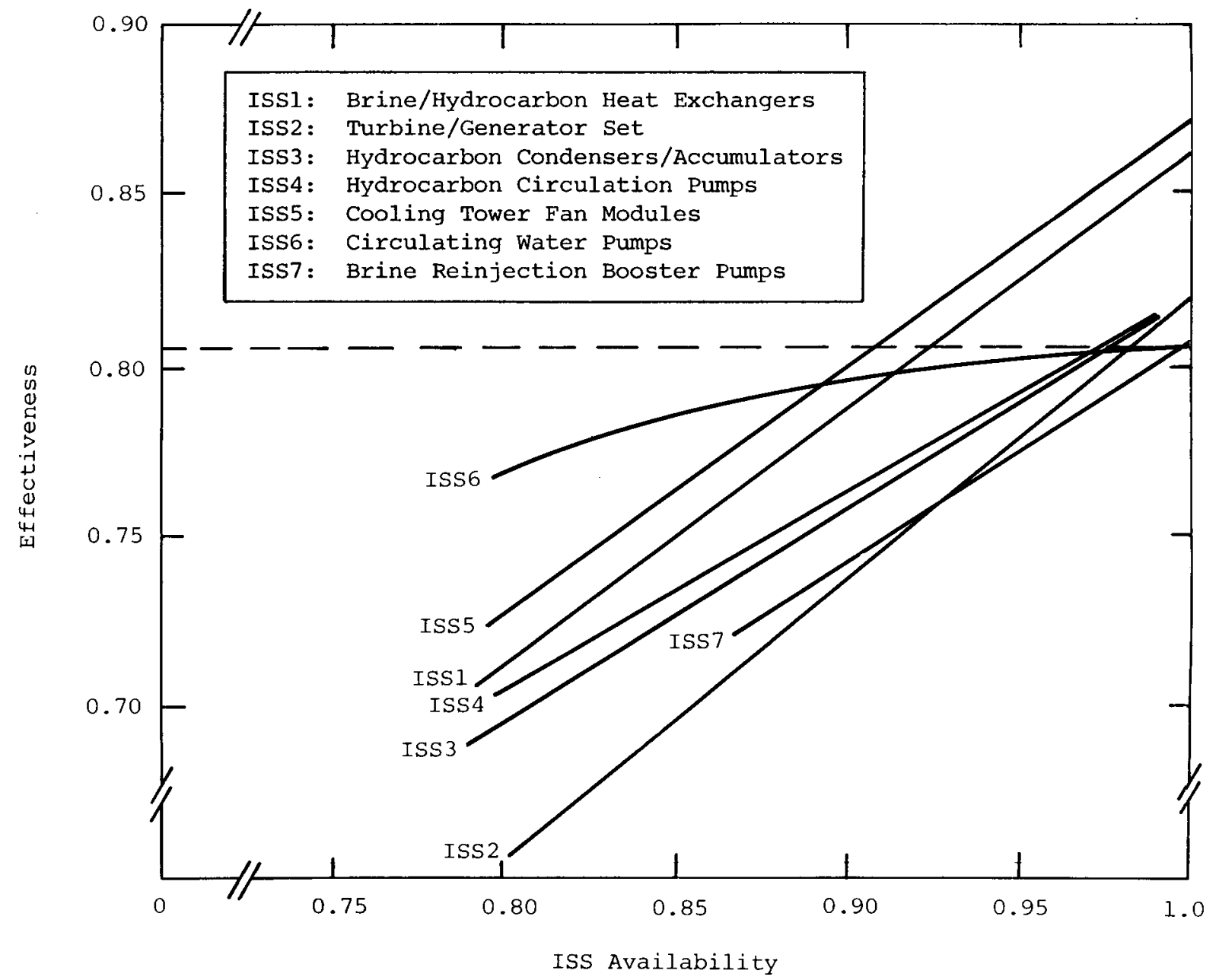

Figure 3-3. Subsystem Sensitivity Analysis 
Component rankings were then developed in accordance with the following criteria:

- Power Lost - the increase in steady-state effectiveness when a component is made perfect.

- Availability - the change in steady-state effectiveness per change in component availability.

- Failure Rate - the change in steady-state effectiveness per change in component failure rate.

- Mean Time to Restore - the change in steady-state effectiveness per change in component mean time to restore.

The expressions used to determine the ranking scores* are presented in Appendix $D$. The resultant rankings are shown in Table 3-4. The table shows that the brine/hydrocarbon heat exchanger represents the most sensitive component, whereas the circulating water pump and motor have a comparatively negligible impact. In terms of their contribution to power lost, the heat exchanger and cooling tower fan modules are the most sensitive, while the turbine/generator is a more distant third.

Improvements in component availability indicate that the turbine/generator and the heat exchanger, in that order, followed closely by the cooling tower fan modules, are the most sensitive. The cooling tower fan is the component most sensitive to an improvement in failure rate, followed by the turbine, hydrocarbon condenser, and generator, in that order. In terms of improvements in repair and restore times, the heat exchanger is most sensitive, followed by the brine reinjection booster pump and the hydrocarbon circulating pump.

It seems clear from these rankings that efforts for system improvement, if economically feasible, should be concentrated on reducing the restore time or increasing the MTBF of the heat exchanger and the cooling tower fan modules, to achieve the most improvement from an availability standpoint. Since economics have not been included in this analysis, capital investment limitations may indicate other actions could be more cost-effective.

\section{RELIABILITY GROWTH}

As part of the baseline data-collection effort, potential areas of reliability improvement were investigated, and, where possible, source estimates of expected growth were obtained. Table 3-5 summarizes the identified potential improvements,

*The score is the numeric result of calculating performance and is a relative number used to demonstrate ranking and the relative magnitude of differences between each ISS. 


\begin{tabular}{|c|c|c|c|c|c|c|c|c|}
\hline & & EBER & $\begin{array}{l}\text { Mable } 3 \\
\text { MPONEN? }\end{array}$ & $\begin{array}{l}4 \\
\text { RANKIN }\end{array}$ & & & & \\
\hline \multirow{3}{*}{ Component } & \multicolumn{8}{|c|}{ Ranking by Criterion } \\
\hline & \multicolumn{2}{|c|}{ Power Lost } & \multicolumn{2}{|c|}{$\begin{array}{l}\text { Component } \\
\text { Availability }\end{array}$} & \multicolumn{2}{|c|}{$\begin{array}{l}\text { Component } \\
\text { Failure Rate }\end{array}$} & \multicolumn{2}{|c|}{$\begin{array}{l}\text { Component } \\
\text { Mean Time } \\
\text { to Restore }\end{array}$} \\
\hline & Score & Rank & Score & Rank & Score & Rank & Score & Rank \\
\hline $\begin{array}{l}\text { Brine/Hydrocarbon } \\
\text { Heat Exchangers }\end{array}$ & 5.92 & 1 & 76.7 & 3 & 10,948 & 5 & 0.03291 & 1 \\
\hline Turbine & 1.16 & 3 & 81.7 & 1 & 29,381 & 2 & 0.00308 & 6 \\
\hline Generator & 0.34 & 7 & 80.9 & 2 & 15,485 & 4 & 0.00173 & 7 \\
\hline $\begin{array}{l}\text { Hydrocarbon Circulating } \\
\text { Pump }\end{array}$ & 0.97 & 4 & 48.4 & 9 & 7,797 & 8 & 0.00586 & 3 \\
\hline $\begin{array}{l}\text { Hydrocarbon Circulating } \\
\text { Motor }\end{array}$ & 0.20 & 9 & 47.6 & 10 & 7,929 & 7 & 0.00120 & 8 \\
\hline Cooling Tower Fan & 5.86 & 2 & 69.7 & 4 & 87,824 & 1 & 0.00367 & 5 \\
\hline Cooling Tower Motor & 0.36 & 6 & 64.1 & 6 & 4,563 & 9 & 0.00504 & 4 \\
\hline Circulating water Pump & 0 & 12 & 1.0 & 12 & 100 & 11 & 0 & 12 \\
\hline Circulating Water Motor & 0 & 11 & 1.0 & 11 & 48 & 12 & 0 & 11 \\
\hline $\begin{array}{l}\text { Brine Reinjection } \\
\text { Booster Pump }\end{array}$ & 0.31 & 8 & 64.5 & 5 & 3,066 & 10 & 0.00645 & 2 \\
\hline Hydrocarbon Condenser & 0.39 & 5 & 51.8 & 7 & 18,645 & 3 & 0.00117 & 9 \\
\hline Hydrocarbon Accumulator & 0.05 & 10 & 51.5 & 8 & 8,633 & 6 & 0.00032 & 10 \\
\hline
\end{tabular}

an estimate of timing relative to the initial plant operation date, and an estimate of the improved MTBFs.

\section{Scenario for Reliability Growth}

The scenario for potential reliability growth for each component in Table 3-5 is described in the following paragraphs. The effect on system availability of each individual subsystem change and the cumulative effects are shown in Table 3-6.

Brine/Hydrocarbon Heat Exchangers (ISS1). Although the carbon steel tubes in the heat exchangers have been tested in contact with the Heber anomaly brine with good 
Table 3-5

POTENTIAL RELIABILITY IMPROVEMENT CANDIDATES

\begin{tabular}{|c|c|c|c|c|c|}
\hline Component & $\begin{array}{c}\text { ISS } \\
\text { Baseline } \\
\text { MTBF } \\
\text { (Hours) }\end{array}$ & $\begin{array}{c}\text { Estimated } \\
\text { Improved } \\
\text { MTBF } \\
\text { (Hours) }\end{array}$ & Improvement & & Assumed Timing \\
\hline $\begin{array}{l}\text { Brine/Hydrocarbon } \\
\text { Heat Exchangers }\end{array}$ & 1,980 & 7,920 & $\begin{array}{l}\text { Change tubing materials } \\
\text { to titanium }\end{array}$ & 5 th & year of operation \\
\hline $\begin{array}{l}\text { Hydrocarbon } \\
\text { Condensers/ } \\
\text { Accumulators }\end{array}$ & 19,147 & 34,165 & $\begin{array}{l}\text { Change tubing materials } \\
\text { to a copper-based alloy }\end{array}$ & 5 th & to 7 th year \\
\hline $\begin{array}{l}\text { Hydrocarbon Circula- } \\
\text { tion Pumps }\end{array}$ & 6,592 & 11,290 & $\begin{array}{l}\text { Change to oil mist } \\
\text { system }\end{array}$ & $3 r d$ & to 7 th year \\
\hline Cooling Tower Fans & 7,011 & 14,020 & $\begin{array}{l}\text { Change fan blading } \\
\text { materials }\end{array}$ & $3 r d$ & to 7 th year \\
\hline $\begin{array}{l}\text { Circulating water } \\
\text { Pump Motors }\end{array}$ & 210,900 & 361,545 & $\begin{array}{l}\text { Manufacturer's estimated } \\
\text { reliability growth }\end{array}$ & 5 th & to loth year \\
\hline $\begin{array}{l}\text { Brine Reinjection } \\
\text { Booster Pumps }\end{array}$ & 9,900 & $19, \dot{800}$ & $\begin{array}{l}\text { Manufacturer's estimated } \\
\text { reliability growth }\end{array}$ & $3 r d$ & to 7 th year \\
\hline
\end{tabular}

results, knowledgeable personnel indicate that fouling and corrosion will cause eventual severe degradation to the brine loop. This corrosion rate will not be uniformly distributed in the tubing and will be intermittent with each shutdown and subsequent descaling operation. The problem is believed to be spot oxidation, resulting from admitting air into the system during planned maintenance operations. Corrosion of the steel tubes will be more rapid in some areas, thereby producing localized penetration of the tubes during operation. Plant availability will degrade as a direct result of these failures. Since there are no known satisfactory methods for preventing air from entering the system or for completely purging it, this type of failure will continue to present a reliability problem and could necessitate design changes.

A potential improvement would be to upgrade tube metallurgy by replacing the carbon steel tubes with more expensive titanium tubes. It is estimated that this change will result in a 400 percent improvement in heat exchanger MTBF, from 1,980 hours to 7,920 hours. The titanium tubes will permit operation of the heat exchangers for a full year without a shutdown for descaling and will also be impervious to Heber brine conditions. Since the change is a major construction effort, it is assumed to occur 
Table 3-6

ESTIMATED CHANGES IN SUBSYSTEM AVAILABILITY AND PLANT EFFECTIVENESS ATTRIBUTED TO RELIABILITY GROWTH

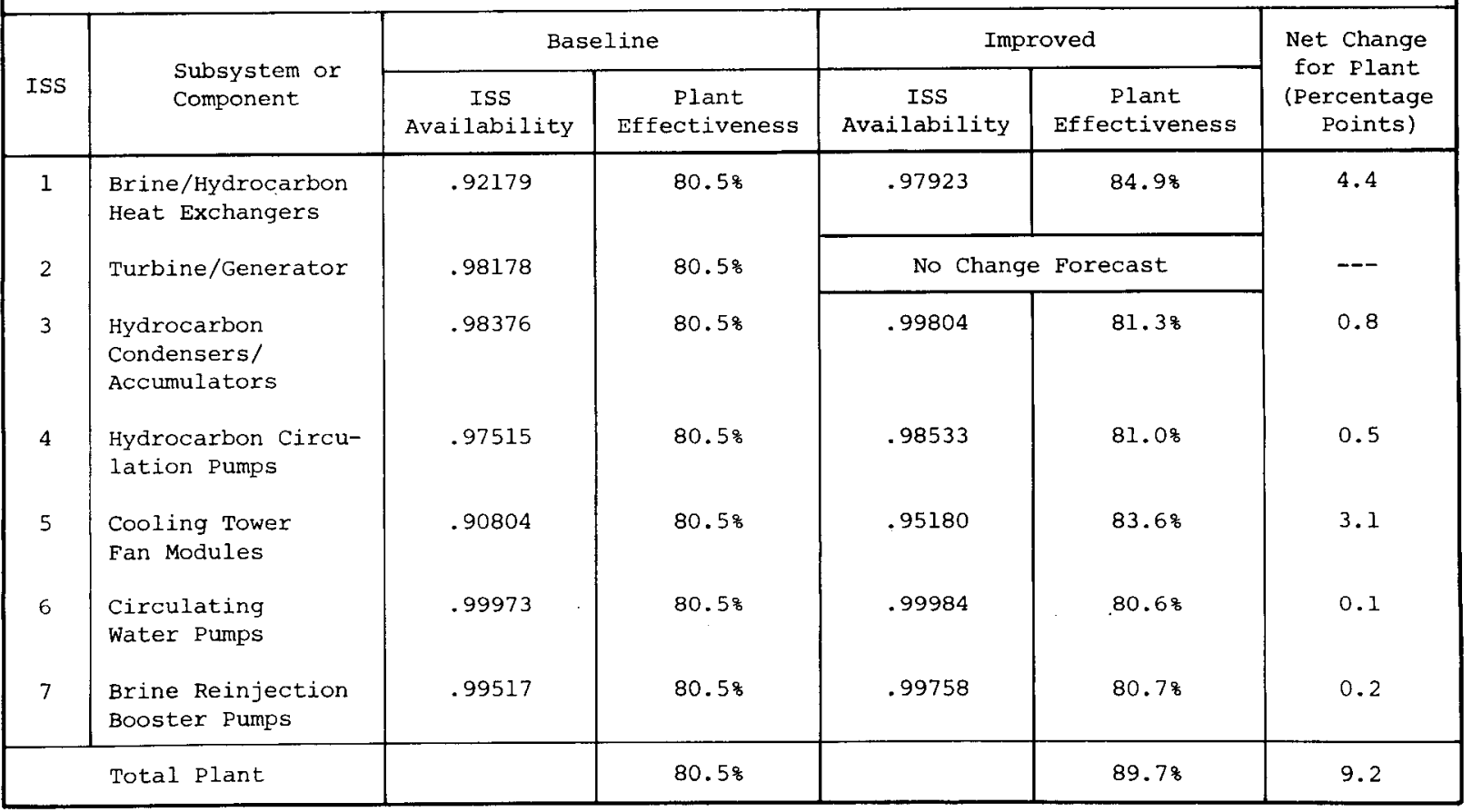

in the fifth year of operation, at which time it is estimated that major overhauls of the heat exchangers would be scheduled. The effect on plant availability as a result of this change is an increase of 4.4 percent.

Hydrocarbon Condensers/Accumulators (ISS3). Irrigation water from the last section of the Imperial Valley system will be the cooling water used in the Heber plant. Despite treatment measures that may be attempted, the quality of this cooling water will degrade from its present level because of the harsh chemicals in the water. Therefore, an increasing number of failures and a more rapid rate of scaling of the carbon steel tubes are expected to occur, resulting in reduced heat transfer rates. Plant output would be degraded, because the condensers can neither be cleaned on line nor isolated, thereby requiring the shutdown of an entire condenser/accumulator stage.

It was assumed in this analysis that the operating utility would begin to retube these condensers during annual outages in the fifth year of operation and continue 
into the seventh year. The choice of tubing for reliability growth would be a copperbased alloy such as Admiralty brass or copper-nickel. These alloys are resistant to the chemical composition of the irrigation water in terms of scaling and tube wall perforations from corrosion. It is predicted that a change to the new alloy would result in reducing the number of tube-wall failures and would extend the time between descaling operations to an annual outage task instead of several times per year. The resultant increase in MTBF is estimated at 34,165 hours, compared with the baseline estimate of 19,147 hours. The effect on plant availability as a result of this change is an increase of 0.8 percent.

Hydrocarbon Circulation Pumps (ISS4). Despite their large size $(2,000 \mathrm{bhp})$, the hydrocarbon circulation pumps are designed using a sleeve-type bearing and pressurized lubrication system. In large pumps, it has been demonstrated that the oil mist system developed recently is more effective than the sleeve bearing system. Both users and designers of similar pumps are predicting an increase in MTBF of 100 percent by using the oil mist design. Since these pumps are critical to plant power lost and are sensitive to changes in restore time from the component-ranking analyses, it is assumed that the operating utility would desire to improve their overall availability in time. Since the pumps are large and costly, a gradual replacement was assumed to take place from the third to the seventh year of operation. Doubling the MTBF of the pump would result in an increase of the subsystem MTBF from 6,592 to 11,290 hours, with a subsequent improvement in plant availability. The effect on plant availability as a result of this change is an increase of 0.5 percent.

Cooling Tower Fan Modules (ISS5). Manufacturers of the fan and motor components anticipate and are planning for reliability improvements. Service life of both components is expected to double by improving fan blade materials, which will result in reduced stress on the motors. Better motor lubrication systems are also planned. These materials will be available when the first components start to fail, in approximately 1.5 to 2 years' time. To improve overall plant availability, it is assumed that the operating utility would repair and replace blades and motors during the third to the seventh year for a complete changeover. The ISS MTBF would increase from 7,011 to 14,020 hours with these improvements. The affect on plant availability as a result of this change is an increase of 3.1 percent.

Circulating water Pumps (ISS6). The components of ISS6 are highly reliable; however, the large motor MTBF is approximately four times lower than that of the pump. Pump motor manufacuters anticipate improvements in both the bearing and lubrication 
system designs, which should result in doubling the service life of the motor. It is assumed that because of the high cost of these items, changeover would be more likely to occur between five and ten years from start up, or when the motors require major overhaul. The resulting improvement in the ISS6 MTBF would increase from 210,900 hours to 361,844 hours. The effect on plant availaiblity as a result of this change is an increase of 0.1 percent.

Brine Reinjection Booster Pumps (ISS7). These pumps are still in the early development stage. As additional moderate temperature geothermal anomalies are used for power generation, designers believe that their early experience will result in at least a 200 percent improvement in service life. These evolutionary changes will improve MTBF from 9,900 to 19,800 hours at the subsystem level and are assumed to take place during the third and seventh year of operation. The effect on plant availability as a result of this change is an increase of 0.2 percent.

\section{Assessing the Impact of Reliability Growth}

The scenario for implementing reliability growth is illustrated in Figure 3-4. The figure depicts growth beginning gradually in the third year of operation and continuing through the tenth year. The resulting impact on plant availability over this period is a growth of slightly more than 9 percent, as shown in Table 3-6. No growth is forecast for the turbine/generator (ISS2), on the basis of the manufacturer's projections of limited growth potential.

In Table 3-6 improvements in plant availability were first calculated individually by changing each subsystem in turn, while holding the remaining subsystems at baseline values. In addition, it is believed that further growth could be achieved by introducing bypass capabilities in the heat exchanger and condenser/accumulator subsystems. This, for example, would permit operation of the plant in additional highercapacity states when a failure occurs in a heat exchanger rather than losing the entire subsystem and dropping to 50 percent capacity. Figure 3-5 presents an approximation of the cumulative reliability growth scenario, using the information depicted by individual subsystem in Figure 3-4. 


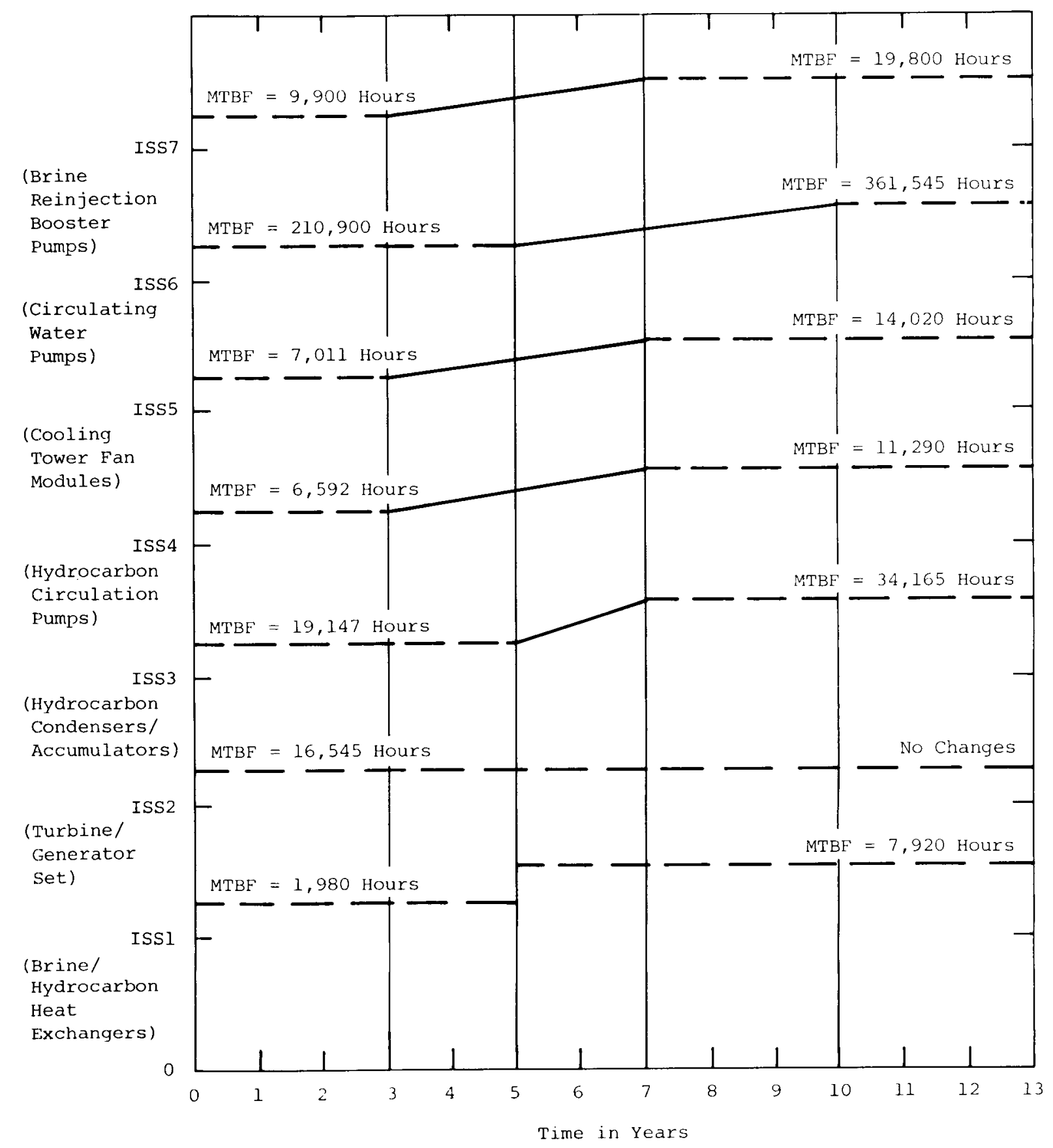

Figure 3-4. Reliability Growth Scenario 


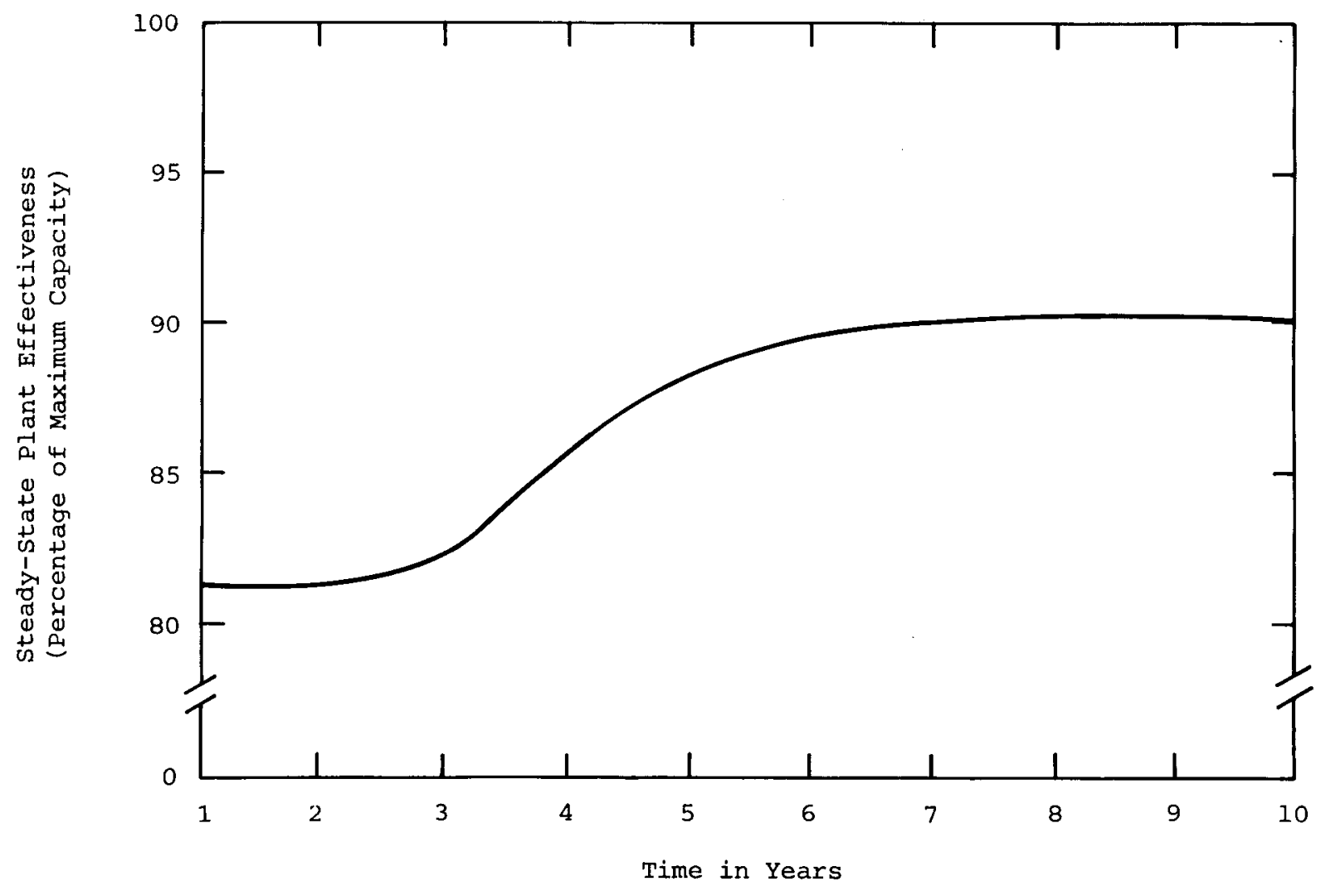

Figure 3-5. Cumulative Effects of Reliability Growth on Steady-State Effectiveness 
Section 4

\section{CONCLUSIONS AND RECOMMENDATIONS}

This section presents the conclusions derived from the evaluation of the Heber Geothermal Demonstration Plant preliminary design and an assessment of areas of potential reliability improvement. Recommendations for future courses of action, on the basis of the results and conclusions, are also provided.

\section{CONCLUSIONS}

In response to the primary objectives of the study, the following general conclusions are presented:

- A geothermal component data base was developed that was sufficient for the initial analysis. The data base should be expanded to provide for improved assessment capability.

- Both a reliability and an availability assessment of the preliminary Heber design was performed, resulting in an inherent reliability of 37.5 days to degrade to 50 percent capacity under no repair conditions and a steady-state availability of 80.5 percent with full maintenance and repair.

- The most critical components in the Heber plant preliminary design are the brine/hydrocarbon heat exchangers (ISSI), with a low MTBF of 1,980 hours. The second most critical are the cooling tower fan modules (ISS5), with a large MTTR of 1,512 hours.

- The sensitivity analyses disclosed that the heat exchangers (ISS1), cooling tower fan modules (ISS5), and turbine/generator (ISS2) are most sensitive to data uncertainties. These results compare favorably with the criticality rankings.

- Changes to the design to enhance plant availability were investigated. Several specific design change recommendations were developed, and further potential areas of design and technology improvement areas were identified.

- The impact of reliability growth on the Heber plant was assessed and a scenario developed to upgrade performance over a seven-year period, beginning with the third year and concluding with the tenth year of operation. The resulting improvement should increase (by 9.2 percent) steady-state availability to 89.7 percent.

- The analysis of the preliminary design shows an 88.5 percent probability of running at 100 percent of rated output for five days. The probability that it can produce at least 75 percent of rated output for 60 days is 72.5 percent. 
- Evaluation of the Heber design, using the baseline data, produced reliability and availability estimates that were equal to or better than previously evaluated gasification-combined-cycle (GCC) and coal-fired plant (CFP) designs. The plant is considered to be more inherently reliable than either of the other advanced technology designs, and the steady-state availability falls between the slightly higher CFP design and the slightly lower GCC design.

\section{RECOMMENDATIONS}

On the basis of the results of the analyses, the following actions are recommended:

- To achieve a higher initial plant availability that would increase the probability of achieving 100 percent output for at least five days and 75 percent output for at least 60 days, certain design changes should be considered, as follows:

--Tubing metallurgy of the brine side of the hydrocarbon/brine heat exchangers should be changed from carbon steel to titanium.

--Tubing metallurgy of the hydrocarbon condensers should be changed from carbon steel to a copper-based alloy.

--Isolation and bypass capabilities should be provided between stages of the hydrocarbon/brine heat exchangers.

--Isolation and bypass capabilities should be provided between sets of hydrocarbon condensers/accumulators.

- Assuming that the Heber Binary Cycle Geothermal Demonstration Plant Project continues as planned, credibility of the results of these analyses can be enhanced by performing the following studies:

- Heat balance calculations for the design should be performed to determine the contribution of each subsystem to overall plant output capacity. These results would be more accurate than the linear estimates used for plant capability in each system state. The analysis could be updated by using these data to increase the accuracy of the assessments.

--Further investigation into the development of an expanded failure and repair data base should be considered. It probably should be based on a more detailed design. While the existing data base is reasonable and sufficient to the analysis, its accuracy could be enhanced by developing data to the levels of indenture for the components of each subsystem developed in the fault trees. While this is difficult in advanced technology designs, it can be accomplished with the cooperation of designers and equipment users and manufacturers. The development of detailed Failure Mode Effects and Criticality Analyses (FMECA) is a technique that can be employed to achieve these more detailed estimates.

--The assessment model can and should be used to update the assessments as the Heber design evolves and also to evaluate candidate design alternatives as they are proposed. These exercises would have the effect of keeping the data base current and would provide a tool for selecting those alternatives that may be most effective. 
--Since this study did not address scenarios for preventive maintenance and the impact of maintenance and logistics support on plant operations, these alternatives should be considered to add credibility to the assessment.

--Consideration should be given to applying this analysis methodology to other geothermal plant designs and to establishing an overall geothermal component failure and repair data base that can support such analysis efforts in the future.

These recommendations do not take into account the effect of capital investment costs but are limited to reliability and availability considerations only. 
Appendix A

FAULT TPEES

Figures A-I through A-7 are graphic representations of the fault trees developed for each independent subsystem (ISS) in the Heber Geothermal Demonstration Plant preliminary design. 


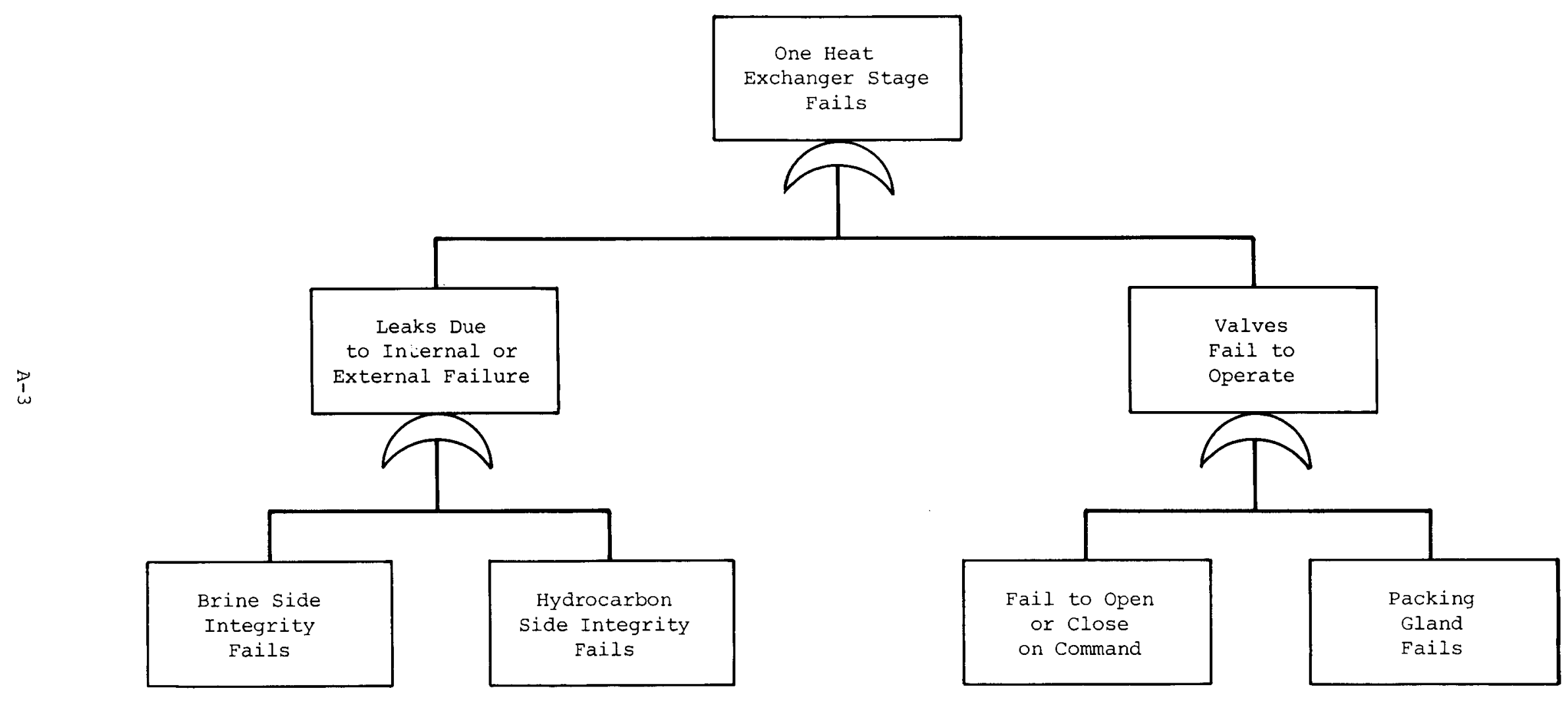

Figure A-1. Fault Tree: ISS1 - Brine/Hydrocarbon Heat Exchangers 


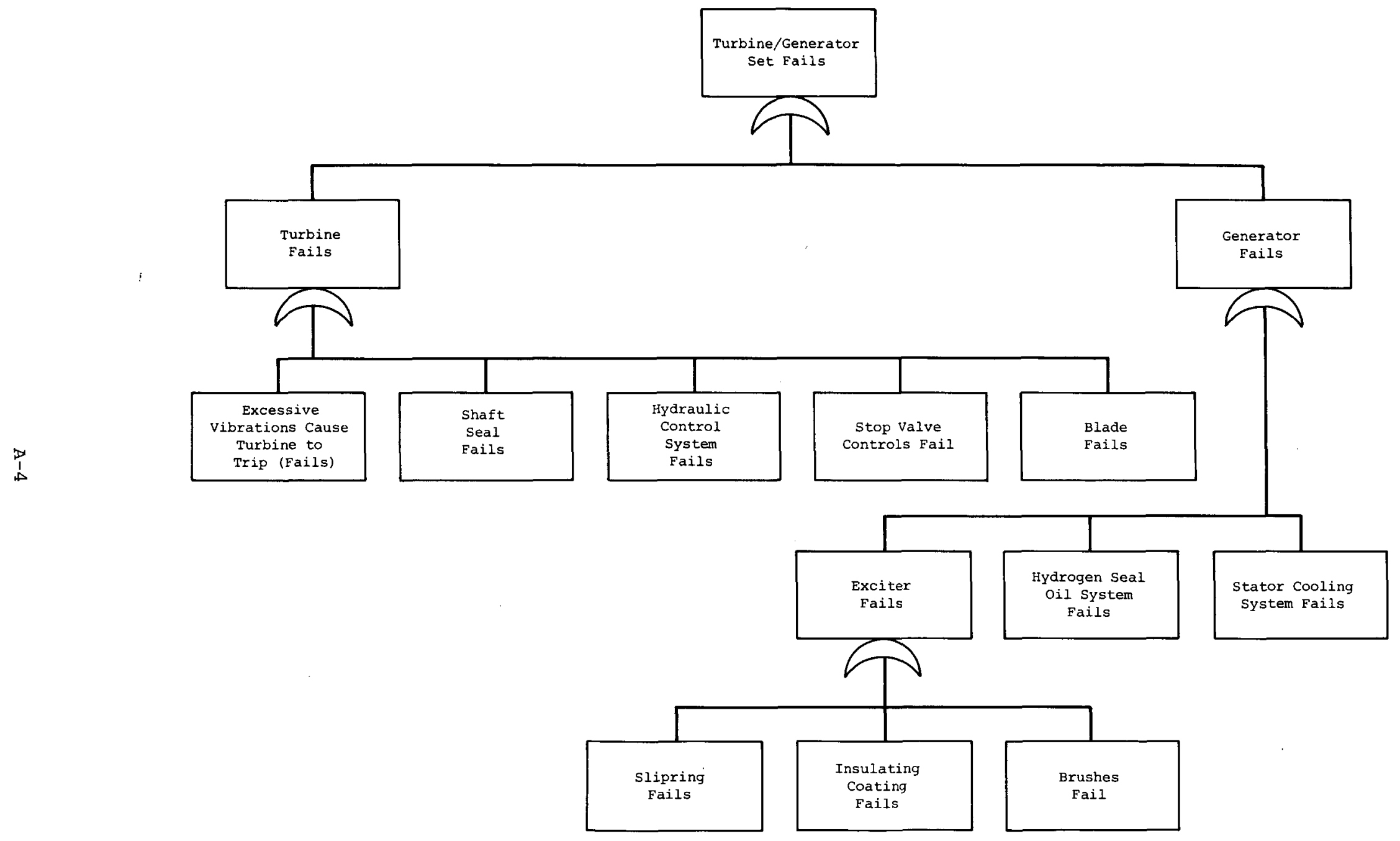

Figure A-2. Fault Tree: ISS2 - ISS2 Turbine/Generator 


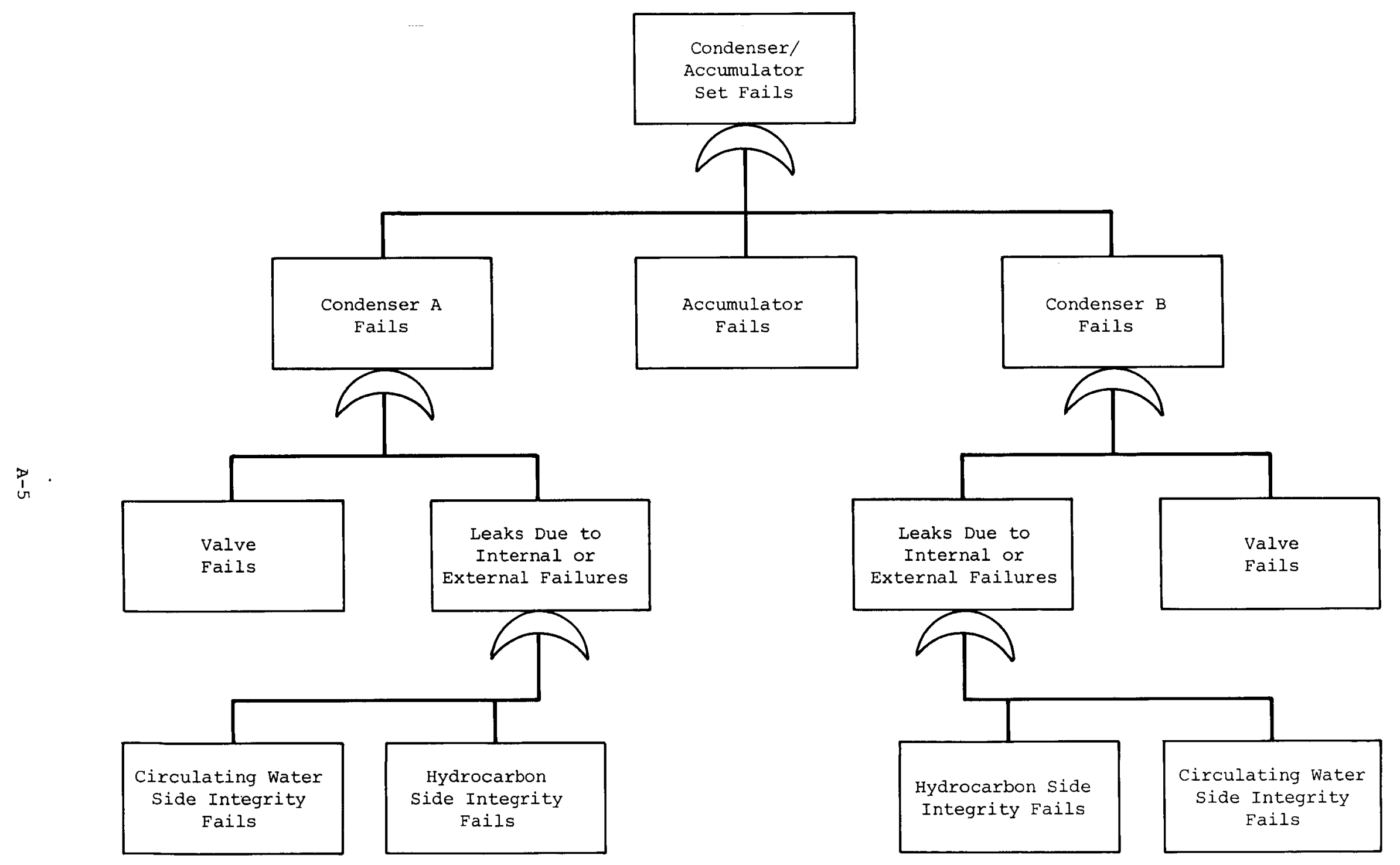

Figure A-3. Fault Tree: ISS3 - Hydrocarbon Condenser/Accumulator 


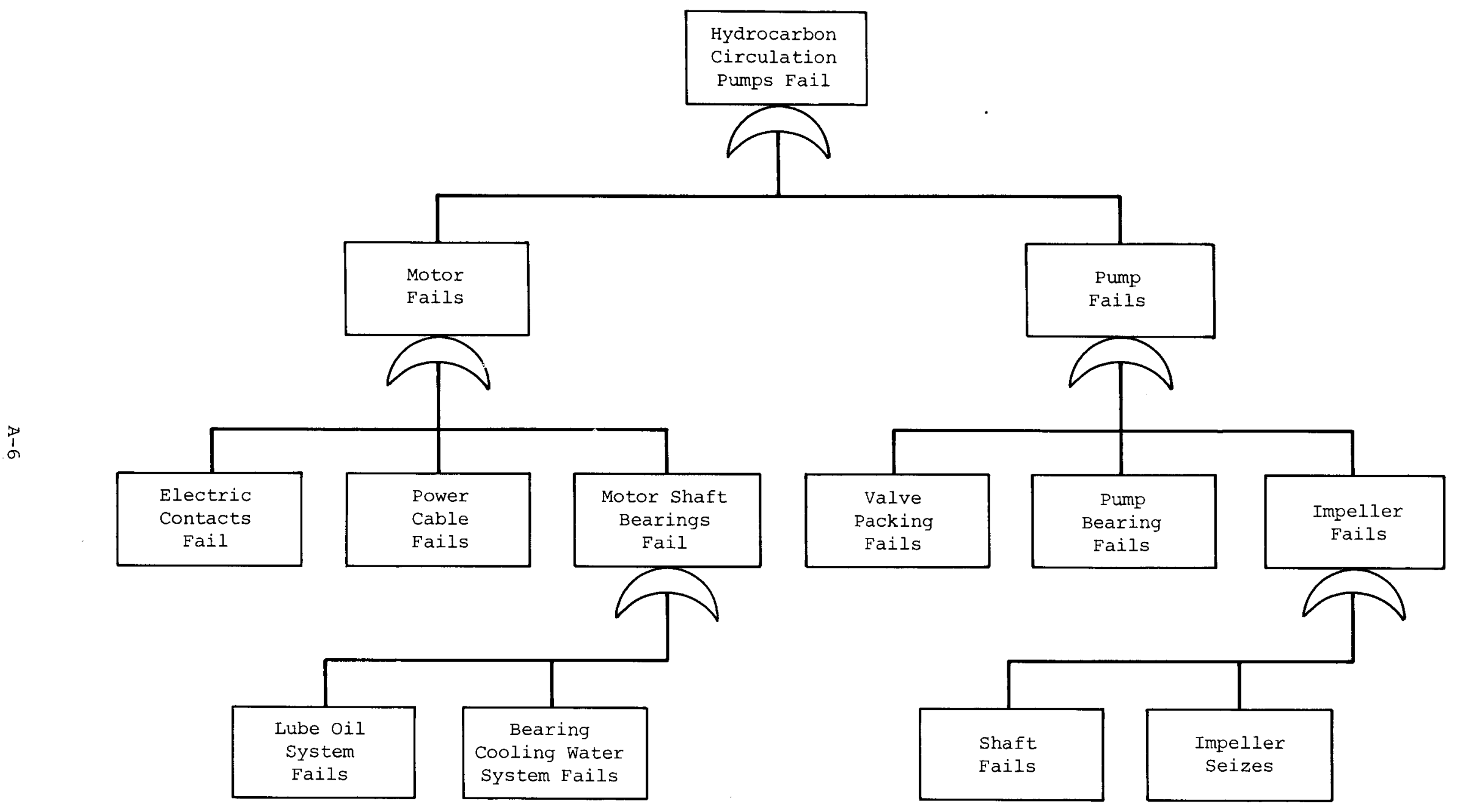

Figure A-4. Fault Tree: ISS4 - Hydrocarbon Circulation Pumps 


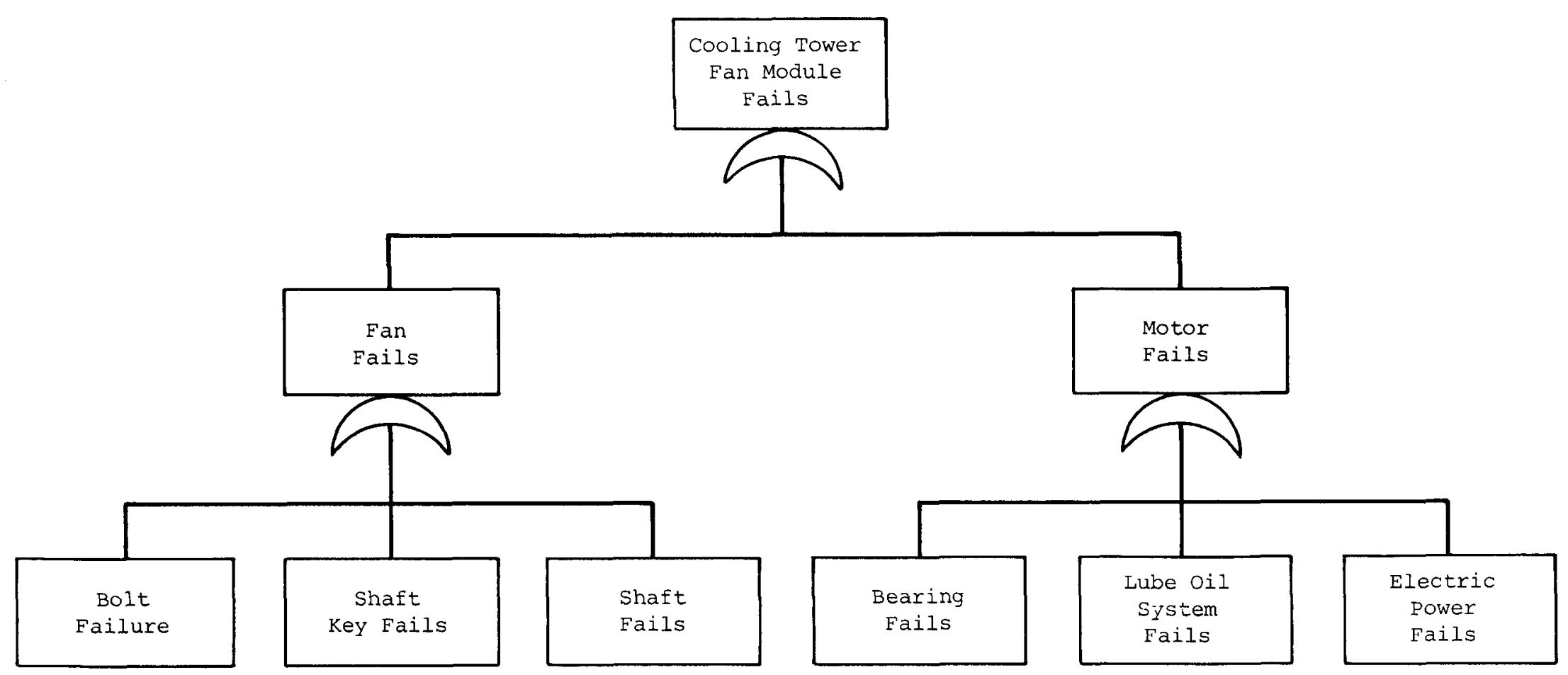

Figure A-5. Fault Tree: ISS5 - Cooling Tower Fan Modules 


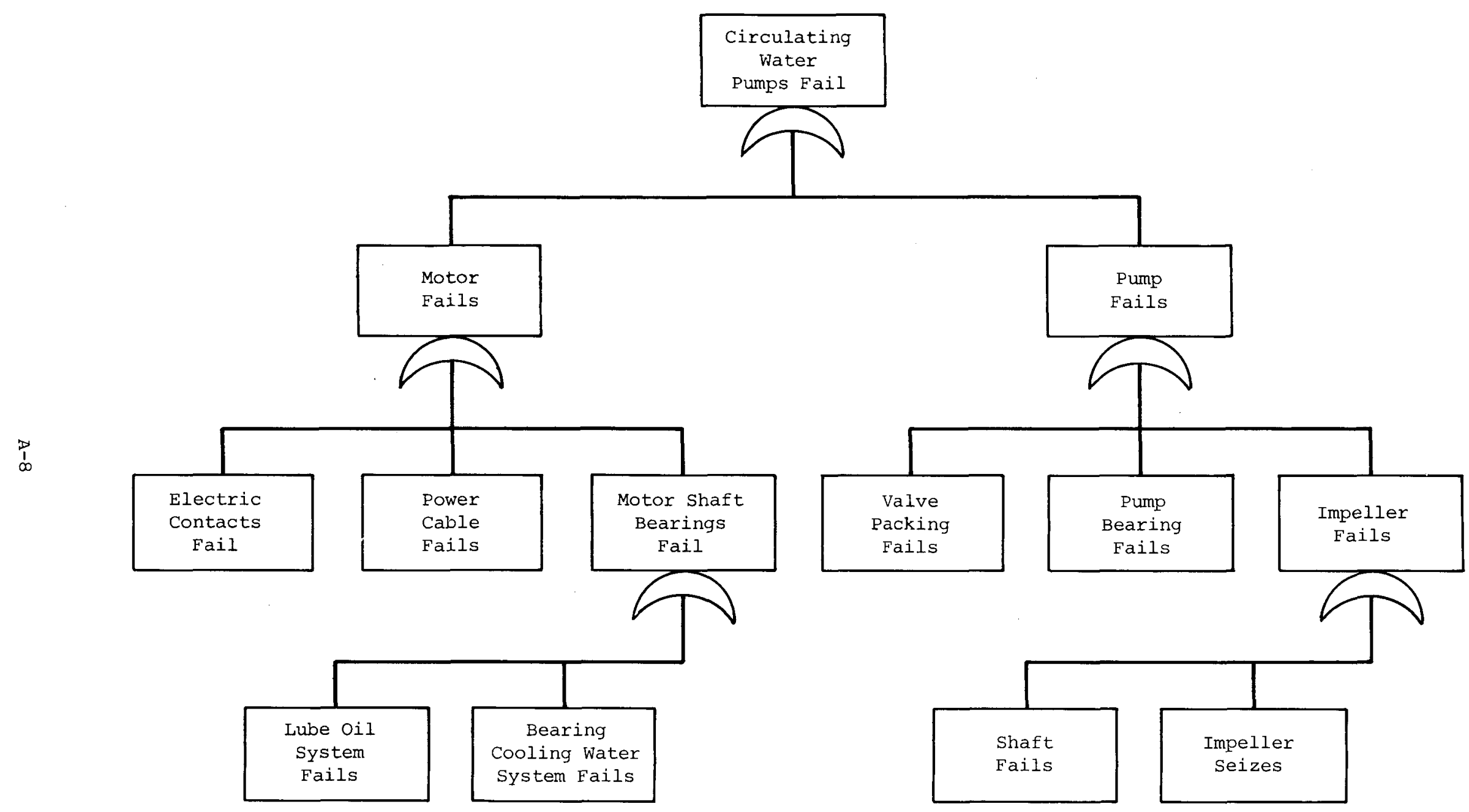

Figure A-6. Fault Tree: ISS6 - Circulating Water Pumps 


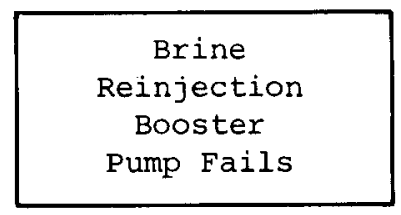

Figure A-7. Fault Tree: ISS7 - Brine Reinjection Booster Pump 


\section{Appendix B}

HEBER COMPONENT DATA SOURCES

Table B-1 lists the sources who provided data for each of the ISSs, including their company affiliation, location, and the type of information provided. 
, 
Table B-1

HEBER COMPONENT DATA SOURCES

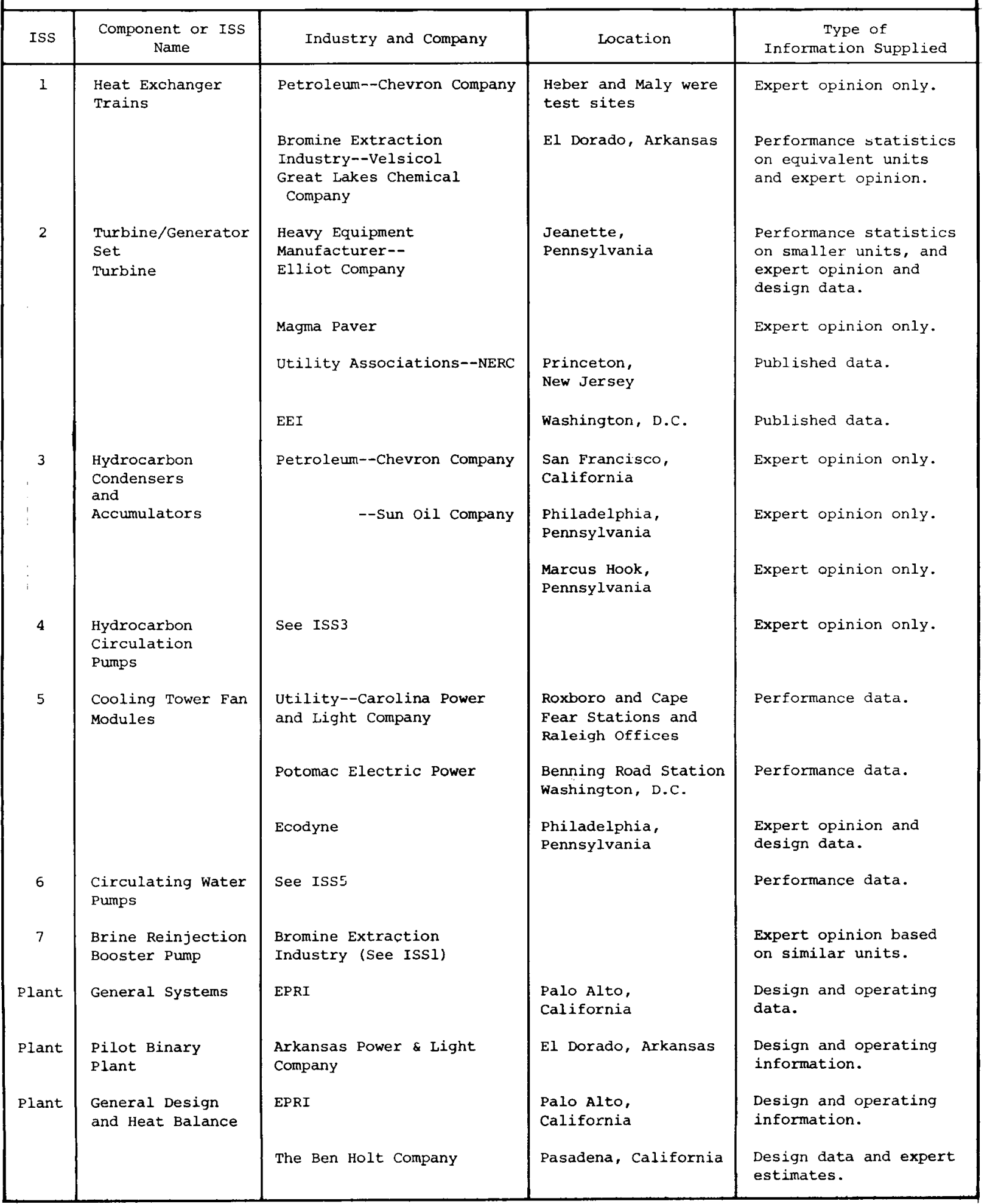




\section{Appendix C}

HEBER FLOW CHART AND PROGRAM LISTING

This appendix presents the flow chart of the Heber analysis program (Figure C-1), accompanied by detailed notes explaining the program logic. In addition, a list of variables used in the program (Table $\mathrm{C}-1$ ) and a computer program listing (Figure C-2) are also provided. 
Lines 00100

through 00280

Lines 00290

through 00470

Lines 00480

through 00540

Iines 00550

through 00650

\section{Lines 00660}

through 00720

\section{Lines 00730 \\ through 01010 \\ see Note 1}

Lines 01020

through 01070

See Note 2

Lines 01080 and 01090
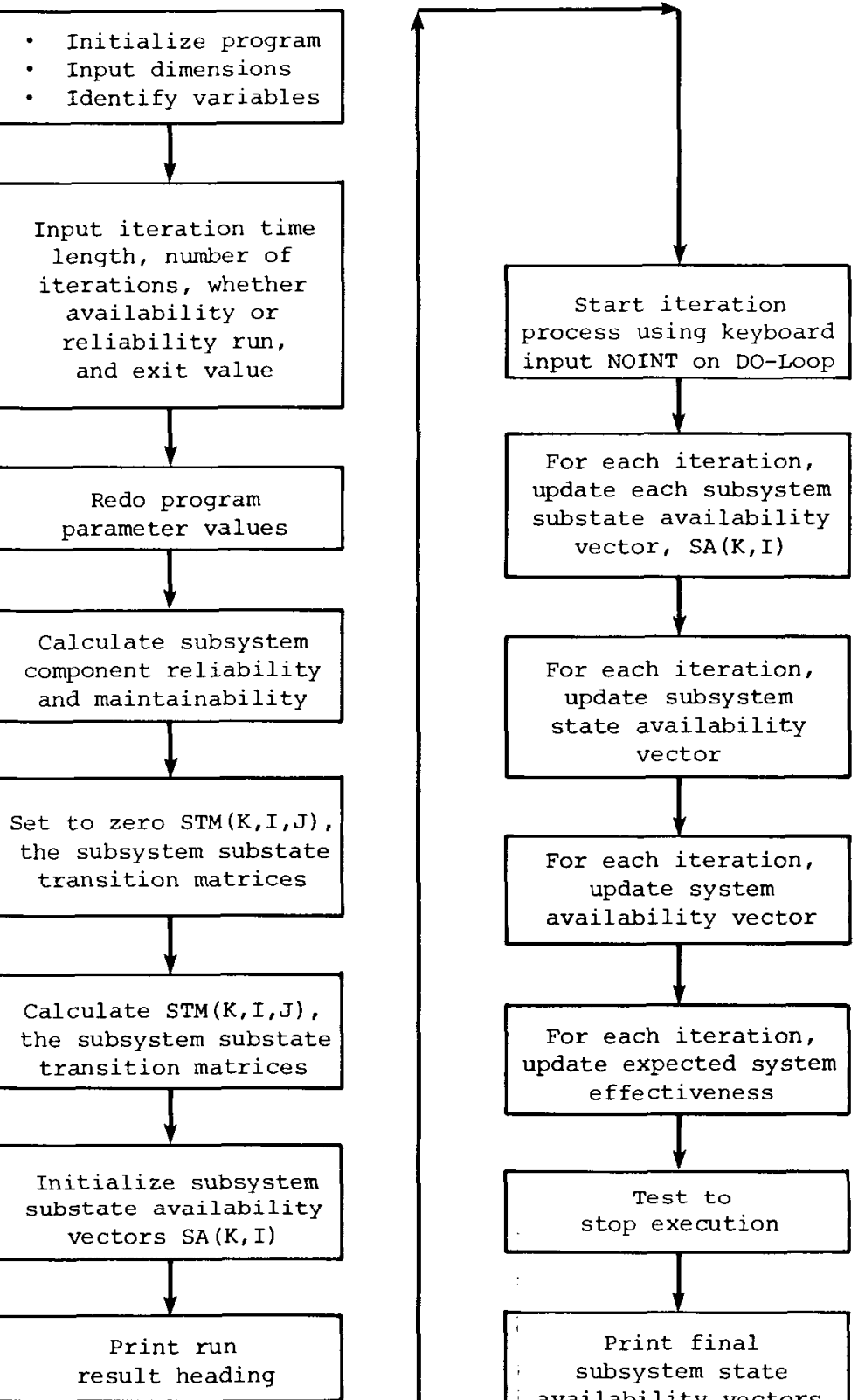

process using keyboard

input NOINT on DO-LoOp

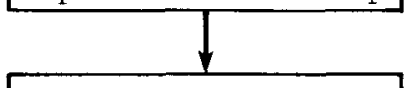

For each iteration, update each subsystem substate availability vector, $S A(K, I)$

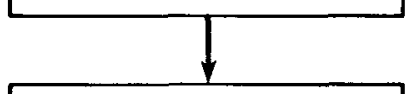

For each iteration, update subsystem

state availability vector

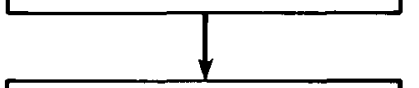

For each iteration, update system availability vector

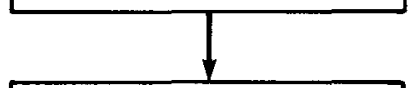

For each iteration, update expected system effectiveness

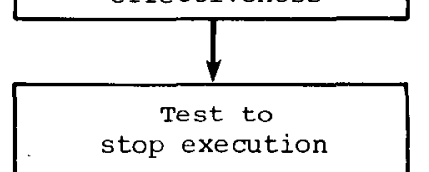

through 01530

See Note 6

Lines 01540

through 01580

see Note 7

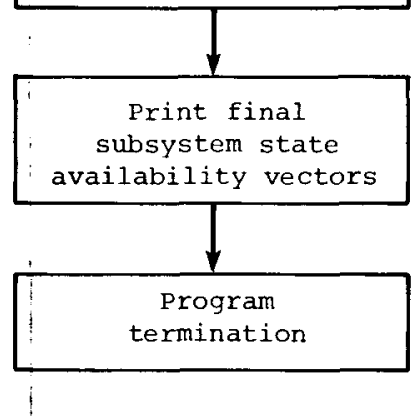

Lines 01590

through 01640

Lines 01650

through 01670

Figure $\mathrm{C}-1$. Heber Hlow Chart 
Note 1:

Each subsystem group can be in $0,1, \ldots, N I S(K)+1$ substates, where NIS(K) is the number of subsystems in subsystem group $\mathrm{K}$. For example, ISSI has two subsystems, hence NIS $(1)=2$. Substate 1 is 0 down, substate 2 is one down, and substate 3 is two, or all, down. It is assumed that in the iteration interval no more than one event will occur, i.e., two or more subsystems cannot fail or be repaired; if one fails, then another cannot be repaired, or if one is repaired, another cannot fail. The possible paths are illustrated in the following chart:

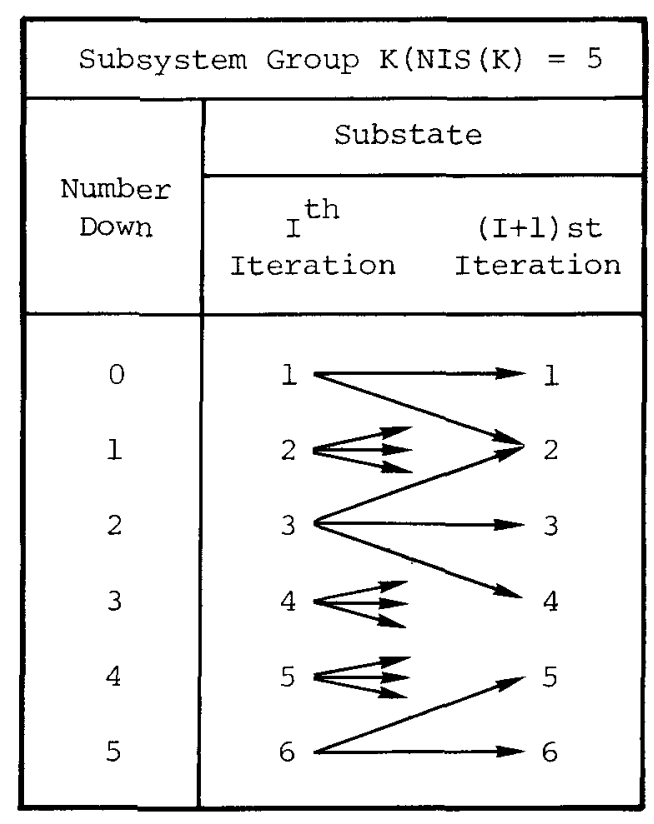

Lines 00860 and 00870 calculate the transition probabilities from substate 1 to the two permitied substates, substates 1 and 2 . To illustrate, to move from substate 1 to substate 1 , none of NIS $(K)$ must fail, thus

$$
\operatorname{STM}(K, 1,1)=R(K) \operatorname{NIS(K)}
$$


To move Erom substate 1 to substate 2, one of NIS(K) can fail, but no others; thus

$$
\operatorname{STM}(K, 1,2)=(\operatorname{NISK}[K]) \times \operatorname{RB}(K) \times R(K) N^{N I S(K)-1}
$$

Lines 00790 through 00810 calculate the remaining transition probabilities. For example, line 00790 calculates the transition probability from substate I to I-1, i.e., I-I down to I-2 down. The variable I4 in the program, equal to I-I, is the number of unavailable (or down) subsystems. It is used as the calculation variable. To move from I4 down to I4-l down, none of the INIS(K)-I4 still up can fail, one of the I4 down can be repaired, and the remaining I4-1 must remain down, thus

$$
\operatorname{STM}(K, I, I-l)=I 4 \times M(K) \times R(K)(N I S(K)-I 4) * M B(K)(I 4-1)
$$

A similar logic governs the remaining expressions.

The allowed transitions do not cover all of the theoretical possibilities, because the transition matrix rows do not sum to 1.0. Iines 00900 through 01010 sum the rows and divide each row element by the normalizing sum. In this way the matrix row sums are set to 1.0 .

The following charts present for each ISS the normalized transition matrices calculated by the program for typical input MTBFs and MTTRs.

\begin{tabular}{|c|c|c|c|}
\hline \multirow{3}{*}{ State } & \multicolumn{4}{|c|}{$\begin{array}{c}\text { Probability of Transitioning } \\
\text { from }\end{array}$} \\
\cline { 2 - 4 } & 1 & 2 & 3 \\
\hline 1 & .987987 & .012013 & 0 \\
2 & .068236 & .926134 & .005630 \\
3 & 0 & .128431 & .871569 \\
\hline
\end{tabular}




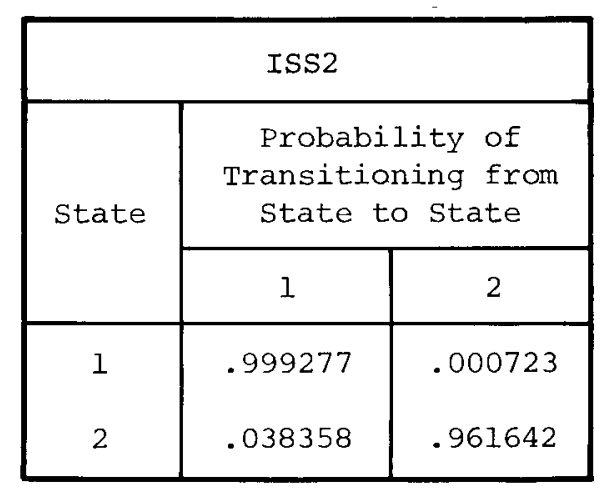

\begin{tabular}{|c|c|c|c|c|c|}
\hline \multirow{2}{*}{ State } & \multicolumn{6}{|c|}{ Probability of Transitioning from State to state } \\
\cline { 2 - 6 } & 1 & 2 & 3 & 4 & 5 \\
\hline 1 & .997499 & .002501 & 0 & 0 & 0 \\
2 & .037231 & .960962 & .001807 & 0 & 0 \\
3 & 0 & .071831 & .927007 & .001162 & 0 \\
4 & 0 & 0 & .104070 & .895369 & .000561 \\
5 & 0 & 0 & 0 & .134180 & .865820 \\
\hline
\end{tabular}

\begin{tabular}{|c|c|c|c|c|c|c|c|}
\hline \multicolumn{8}{|c|}{ ISS4 } \\
\hline \multirow{2}{*}{ State } & \multicolumn{7}{|c|}{ Probability of Transitioning from State to State } \\
\cline { 2 - 8 } & 1 & 2 & 3 & 4 & 5 & 6 & 7 \\
\hline 1 & .989185 & .010815 & 0 & 0 & 0 & 0 & 0 \\
2 & .073119 & .918513 & .008368 & 0 & 0 & 0 & 0 \\
3 & 0 & .136487 & .857265 & .006248 & 0 & 0 & 0 \\
4 & 0 & 0 & .240853 & .756391 & .002756 & 0 & 0 \\
5 & 0 & 0 & 0 & .284337 & .714361 & .001302 & 0 \\
6 & 0 & 0 & 0 & 0 & .284337 & .714361 & .001302 \\
7 & 0 & 0 & 0 & 0 & 0 & .323243 & .676757 \\
\hline
\end{tabular}




\begin{tabular}{|c|c|c|c|c|c|c|c|c|}
\hline \multicolumn{10}{|c|}{ ISS5 } \\
\hline \multirow{2}{*}{ State } & \multicolumn{7}{|c|}{ Probability of Transitioning from State to State } \\
\cline { 2 - 8 } & 1 & 2 & 3 & 4 & 5 & 6 & 7 & 8 \\
\hline 1 & .988149 & .011851 & 0 & 0 & 0 & 0 & 0 & 0 \\
2 & .016603 & .973390 & .010007 & 0 & 0 & 0 & 0 & 0 \\
3 & 0 & .032718 & .959066 & .008216 & 0 & 0 & 0 & 0 \\
4 & 0 & 0 & .048365 & .945158 & .007477 & 0 & 0 & 0 \\
5 & 0 & 0 & 0 & .063565 & .931646 & .004789 & 0 & 0 \\
6 & 0 & 0 & 0 & 0 & .078336 & .918516 & .003148 & 0 \\
7 & 0 & 0 & 0 & 0 & 0 & .092697 & .905751 & .001552 \\
3 & 0 & 0 & 0 & 0 & 0 & 0 & .106664 & .893356 \\
\hline
\end{tabular}

\begin{tabular}{|c|c|c|c|c|}
\hline \multicolumn{5}{|c|}{ ISS6 } \\
\hline \multirow{3}{*}{ State } & \multicolumn{4}{|c|}{$\begin{array}{c}\text { Probability of Transitioning } \\
\text { from State to State }\end{array}$} \\
\cline { 2 - 5 } & 1 & 2 & 3 & 4 \\
\hline 1 & .999829 & .000171 & 0 & 0 \\
2 & .190848 & .809060 & .000092 & 0 \\
3 & 0 & .320536 & .679425 & .000039 \\
4 & 0 & 0 & .414405 & .585595 \\
\hline
\end{tabular}

\begin{tabular}{|c|c|c|c|}
\hline \multirow{4}{*}{ State } & \multicolumn{4}{|c|}{$\begin{array}{c}\text { ISS } 7 \\
\text { frobability of Transitioning } \\
\text { from }\end{array}$} & 1 & 2 & 3 \\
\cline { 2 - 4 } & 1 & .002420 & 0 \\
\hline 1 & .997580 & .778066 & .000944 \\
2 & .220990 & .362266 & .637734 \\
\hline 3 & 0 & & \\
\hline
\end{tabular}


Note 2:

This section initializes the ISS substate availability vectors. For example, ISS5 has seven subsystems; thus it has eight substates. It is assumed that none of these subsystems are down prior to the first iteration, thus

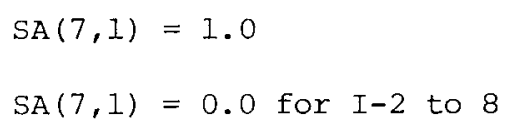

Note 3:

If $\mathrm{SA}(\mathrm{K}, \mathrm{I})$ is the value of the $\mathrm{K}$ subsystem substate availability vector on the $I^{\text {th }}$ iteration, its value on the next iteration is generated by this section. With appropriate program DO LOOPS, the following vector $\times$ matrix multiplication is executed for each ISS:

\begin{tabular}{|c|c|}
\hline \multicolumn{2}{|c|}{ Iteration } \\
\hline For $J$ & For $J+1$ \\
\hline $\operatorname{SA}_{\mathrm{J}}(\mathrm{K}, \mathrm{J})=\mathrm{SA}_{\mathrm{J}+\mathrm{I}}(\mathrm{K}, \mathrm{J}) \times \operatorname{STM}(\mathrm{K}, \mathrm{I}, \mathrm{J})$ \\
\hline
\end{tabular}

The row vector $S A(K, J)$ is multiplied element-by-element by the column elements of: $\operatorname{STM}(K, I, J)$, and the element products are summed to produce the elements of the next value of $S A(K, J)$.

\section{Note 4:}

The system state matrix identifies for each subsystem group the number of subsystems down in each system state. Some states specify an integer, e.g., 0, 1, up to NIS $(K)$. Others specify that the state is defined by some number less than some integer, e.g., <6, which means that the state exists if $0,1,2,3,4$, or 5 subsystems are down. The system state matrix $\mathrm{S}(\mathrm{J}, \mathrm{K})(\mathrm{J}=1,25, \mathrm{~K}=1,7)$ shows a single integer value as positive numbers and multiple integer values as negative numbers. Thus, if $\mathrm{S}(2,3)=2$ (system state 2, subsystem 3), it means exactly two subsystems of subsystem group 3 are down. If $S(2,4)=-3$, it means that zero, one, or two subsystems of ISS4 are down.

The IF statement at line 01290 tests which condition exists. The following flow diagram illustrates the logic of lines 01270 through 10410: 
$(J L=25)$

DO $145 \mathrm{~J}=1, \mathrm{JL}$

$(\mathrm{KI}=7)$

Single integer down

Defines subsystem state as number down +1

$\mathbf{T}(\mathbf{K}, J)$ is a temporary variable assigned the value of the subsystem state availability.
DO $150 \mathrm{~K}=1, \mathrm{KI}$

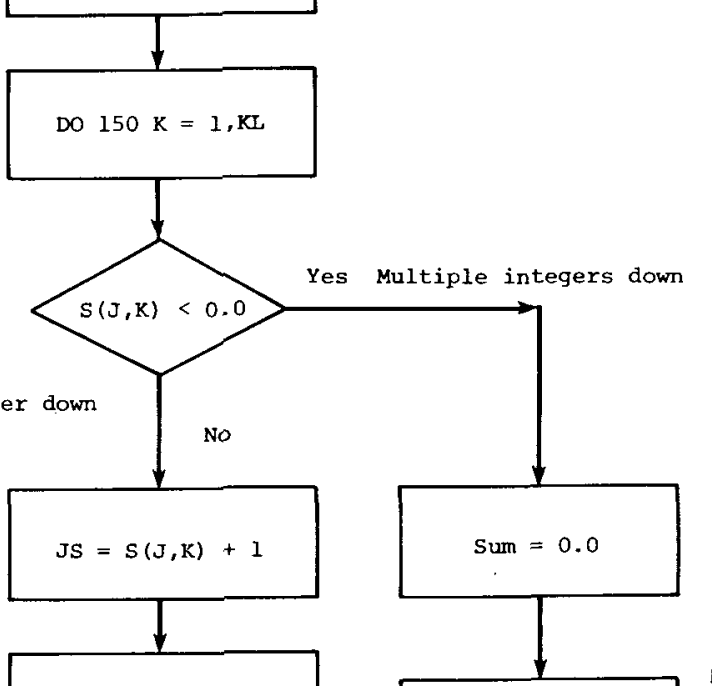

$\mathrm{T}(\mathrm{K}, \mathrm{J})=\mathrm{SA}(\mathrm{K}, \mathrm{JS})$

$M M M=\operatorname{IABS}[S(J, K)]$

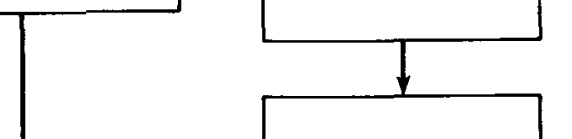

DO $170 \mathrm{~J} 2=1, \mathrm{MMM}$

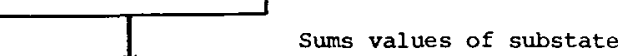
probabilities from 1 to absolute value of $S(J, K)$. Thus, if $\mathrm{S}(\mathrm{J}, \mathrm{K})=-3$, it sums $S A(K, 1), S A(K, 2)$, $S A(K, 3)$, corresponding to $\operatorname{SUM}=\mathrm{SUM}+\mathrm{SA}(\mathrm{K}, \mathrm{J} 2)$ 0,1 , or 2 components down.

170 Continue

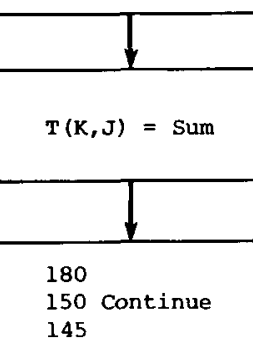

$T(K, J)$ now contains the probability for each system's state that the subsystems are in the configuration as specified by the state matrix. 


\section{Note 5:}

To reiterate, the $\mathrm{T}(\mathrm{K}, \mathrm{I})$ calculated above contains, for each system state, the probability that each ISS will be in the substate specified by the state matrix. To transform these probabilities into a system state availability, the product is taken of all substate probabilities in a state definition. Thus, if $A V(I)$ is the system state availability, then

$$
\mathrm{AV}(\mathrm{I})=\prod_{\mathrm{K}=1}^{7} \mathrm{~T}(\mathrm{~K}, \mathrm{I})
$$

This product is formed in program Iines 01420 through 01480 .

Note 6:

The $\mathrm{AV}(I), I=1,25$, are calculated at each iteration. To obtain the expected system effectiveness for each iteration, the vector scalar product of $A V$ and $C$ is calculated

$$
\mathrm{EFF}=\mathrm{AV} \times \mathrm{C}=\sum_{J=1}^{25} \mathrm{AV}(I) \times \mathrm{C}(I)
$$

This operation is performed in program lines 01490 through 01530 .

Note $7:$

There are two ways to stop program iteration. One way is to allow the program to stop after the keyboard-entered run length, NOINT, is encountered at Iine 01580 . The other is to allow the program to stop when the current value of expected effectiveness differs from the last by less than the keyboard-entered variable, PCNTC. Lines 01540 through 01580 execute this option. (The idea is to terminate a run if the values of effectiveness have ceased to change to a significant degree.) 
Table C-I

PROGRAM VARIABLES

\begin{tabular}{|c|c|c|}
\hline Variable & Characteristic & Description \\
\hline AV & Real, Vector (25) & System state availability \\
\hline $\mathrm{C}$ & Real,vector (25) & System state effectiveness \\
\hline DELT & Real & Iteration time interval \\
\hline $\mathrm{EFF}$ & Real & $\begin{array}{l}\text { System effectiveness calculated at } \\
\text { each iceration, } E F F=A V C\end{array}$ \\
\hline EFFL & Real & $\begin{array}{l}\text { System effectiveness calculated at } \\
\text { each iteration, } E F F=A V C\end{array}$ \\
\hline$I, I L, I L I, I 4$ & Integers & Durmy variables \\
\hline $\mathrm{J}, \mathrm{JL}, \mathrm{JS}, \mathrm{J} 2$ & Integers & Dummy variables \\
\hline $\mathrm{K}, \mathrm{KL}, \mathrm{KL}$ I, KO & Integers & Dumny variables \\
\hline $\mathrm{M}, \mathrm{MB}$ & Real, vector (7) & $\begin{array}{l}\text { Maintainability and nonmaintainability } \\
\text { of each subsystem }\end{array}$ \\
\hline MMM & Durmy & \\
\hline MTBF , MTTR & Real, vector (7) & $\begin{array}{l}\text { Mean time between failures and mean } \\
\text { time to repair for each subsystem }\end{array}$ \\
\hline NIS & Integer (7) & Number of components in each subsystem \\
\hline NOINT & Integer & $\begin{array}{l}\text { Keyboard input; the number of iterations } \\
\text { desired for the run }\end{array}$ \\
\hline NRFLG & Integer & $\begin{array}{l}\text { Flag used by program to distinguish } \\
\text { between reliability and availability } \\
\text { runs }\end{array}$ \\
\hline PCNTC & Real & $\begin{array}{l}\text { Keyboard input used by program to } \\
\text { terminate a run when the percentage } \\
\text { change in effectiveness falls below } \\
\text { this amount }\end{array}$ \\
\hline $\mathrm{R}, \mathrm{RB}$ & Real, vector (7) & Subsystem reliability and unreliability \\
\hline s & Real, Matrix $(25,7)$ & System state matrix \\
\hline SA & Real, Matrix $(7,8)$ & Subsystem state availabilities \\
\hline STM & Real, Matrix $(7,8,8)$ & Subsystem transition matrices \\
\hline SUM & Dummy & \\
\hline $\mathrm{T}$ & Real, Matrix $(7,25)$ & $\begin{array}{l}\text { For each subsystem, } T \text { is the probability } \\
\text { that it will be in each of the } 25 \text { states; } \\
\text { used to calculate system-state probabilities }\end{array}$ \\
\hline TEST & Dummy & \\
\hline TV & Dummy & Used in the transformation of $\mathrm{T}$ and $\mathrm{AV}$ \\
\hline
\end{tabular}




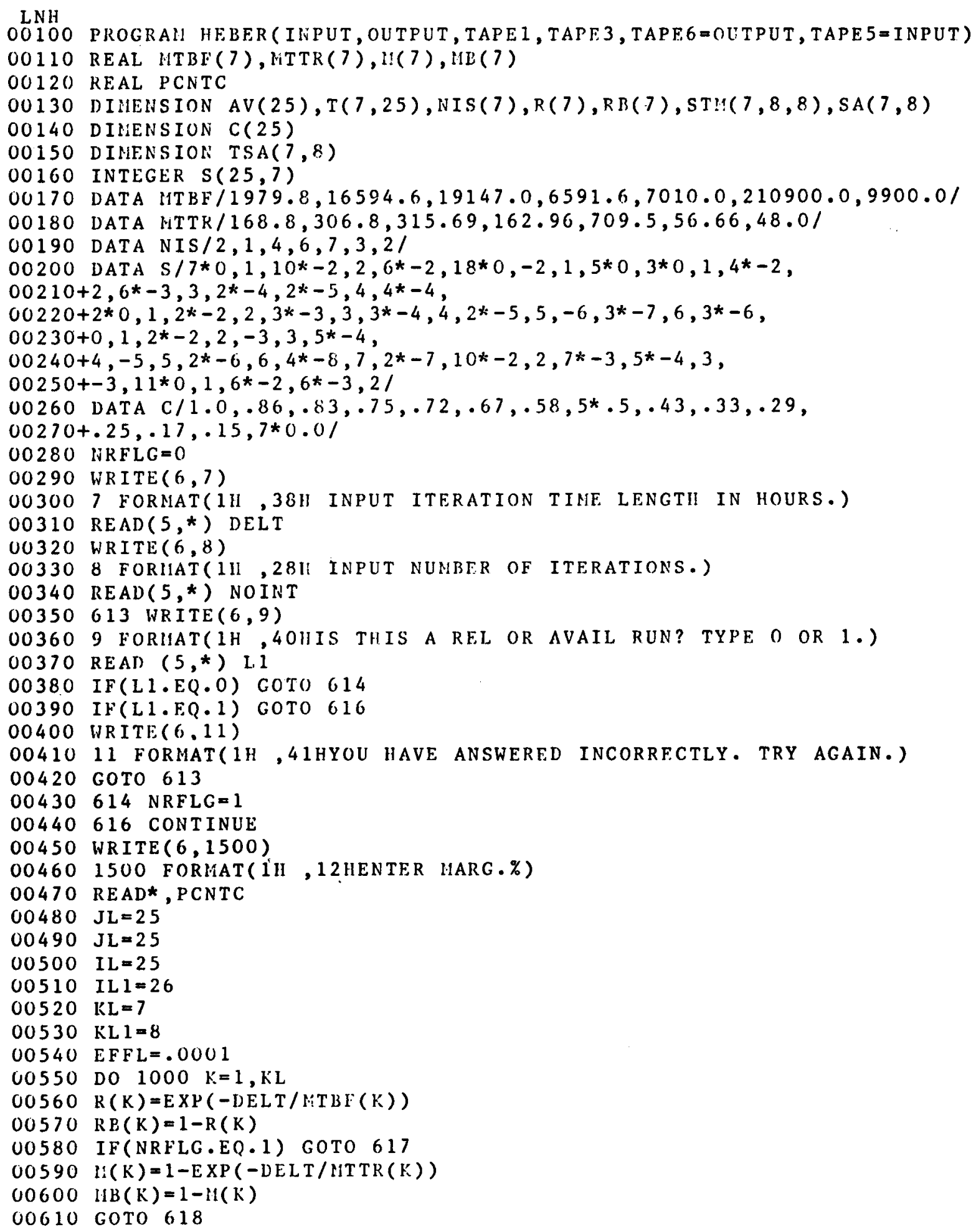




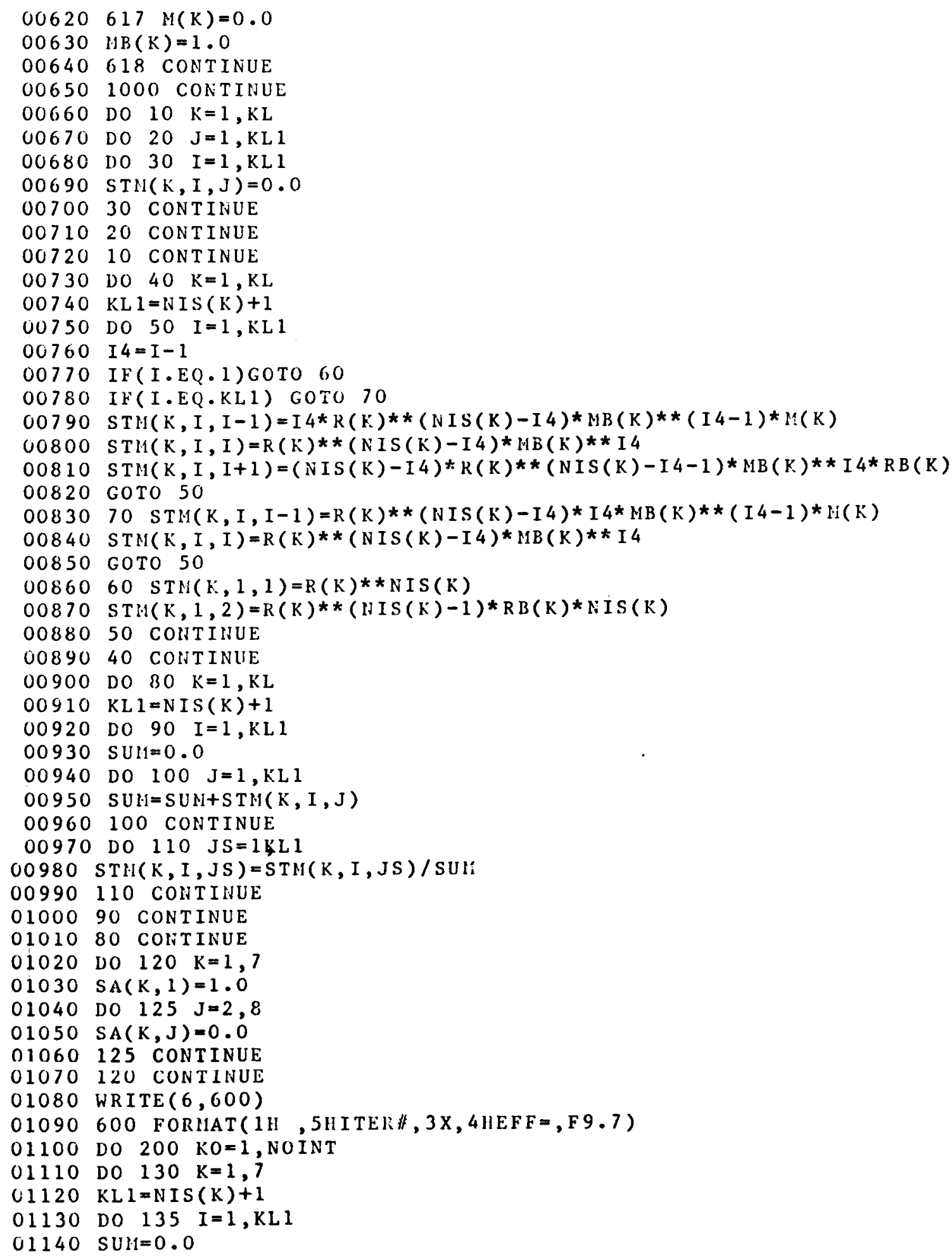




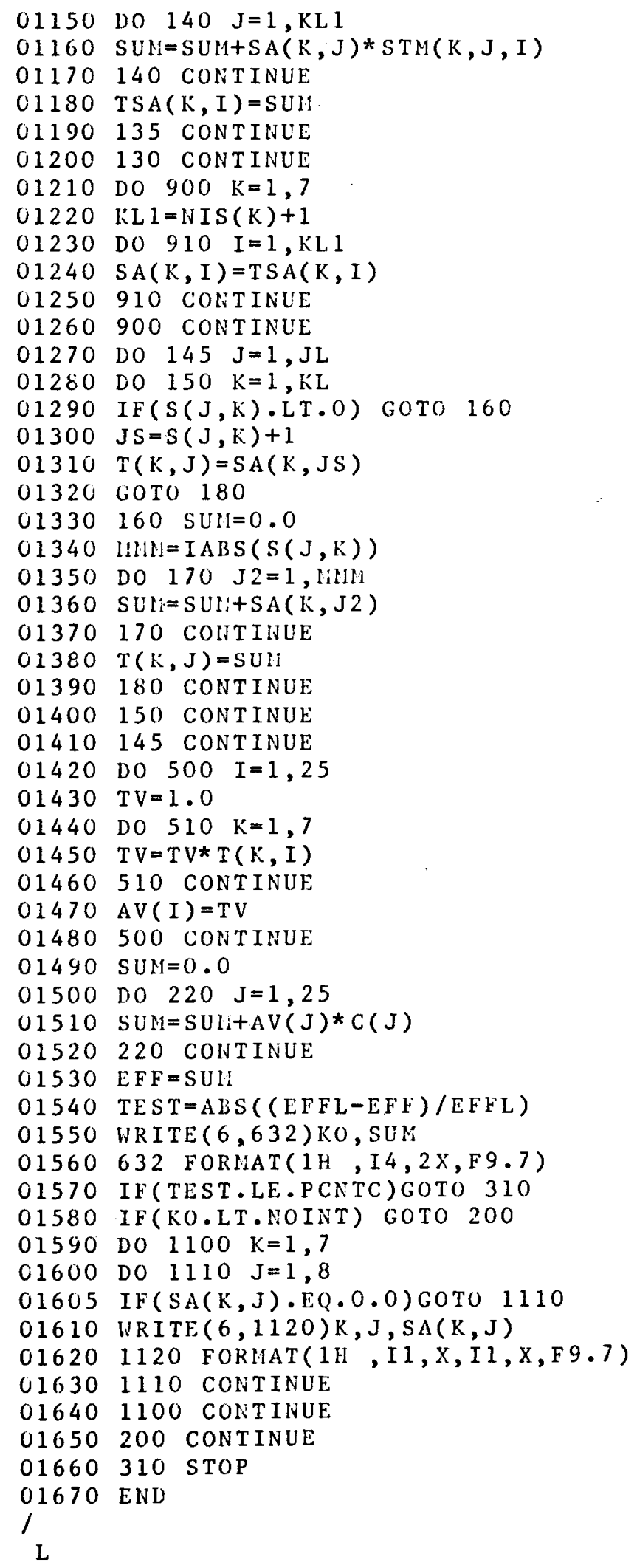

Figure C-2. (continued) 


\section{Appendix D}

\section{COMPONENT-RANKING EXPRESSIONS}

This appendix presents the mathematical formulations employed in obtaining scores for the component-ranking criteria used in the analysis. These criteria are representative of power lost, availability, failure rate, and mean time to restore.

$$
\begin{aligned}
& \text { Power Lost }=\operatorname{Lim}_{A_{i j} \rightarrow 1}\left(E_{s s}\right)-E_{S S} \\
& \text { Availability }=\frac{\delta E_{S S}}{\delta A_{i j}}=\frac{\delta E_{S S}}{\delta A_{i}} \frac{\delta A_{i}}{\delta A_{i j}} \\
& \text { Failure Rate }=\frac{\delta E_{S S}}{\delta \lambda_{i j}}=\frac{\delta E_{s S}}{\delta A_{i}} \frac{\delta A_{i}}{\delta A_{i j}} \frac{\delta A_{i j}}{\delta \lambda_{i j}}=\frac{\delta E_{S S}}{\delta A_{i}} A_{i} A_{i j} \tau_{i j} \\
& \underset{\text { Mean Time to }}{\text { Restore }}=\frac{\delta E_{S S}}{\delta A_{i}} \frac{\delta A_{i}}{\delta A_{i j}} \frac{\delta A_{i j}}{\delta \lambda_{i j}}=\frac{\delta E_{S S}}{\delta A_{i}} A_{i} A_{i j} \lambda_{i j}
\end{aligned}
$$

where

$$
E_{S S}=\text { the steady-state effectiveness measure of the plant }
$$

$$
\begin{aligned}
& \frac{\delta E}{\delta A_{i}}=\text { the change in the steady-state effectiveness resulting from } \\
& \text { from the sensitivity exercises of the model } \\
& A_{i j}=\text { the availability of the } j^{\text {th }} \text { component in the } i \text { th subsystem } \\
& =\frac{1}{\lambda_{i j} \tau_{i j}+1} \\
& \lambda_{i j}=\text { the } j^{\text {th }} \text { component in the } i^{\text {th }} \text { subsystem failure rate } \\
& \tau_{i j}=\text { the } j^{\text {th }} \text { component in the } i^{\text {th }} \text { subsystem mean time to restore }
\end{aligned}
$$

